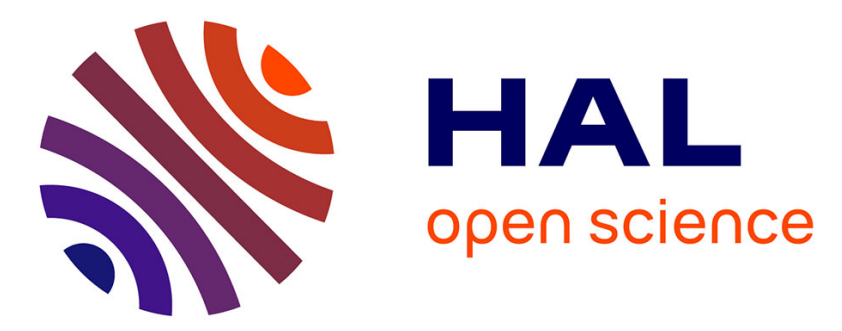

\title{
Stress and deformation mechanisms at a subduction zone: insights from 2-D thermomechanical numerical modelling
}

Annelore Bessat, Thibault Duretz, György Hetényi, Sébastien Pilet, Stefan M Schmalholz

\section{To cite this version:}

Annelore Bessat, Thibault Duretz, György Hetényi, Sébastien Pilet, Stefan M Schmalholz. Stress and deformation mechanisms at a subduction zone: insights from 2-D thermomechanical numerical modelling. Geophysical Journal International, 2020, 221 (3), pp.1605-1625. 10.1093/gji/ggaa092 . insu-02873025

\section{HAL Id: insu-02873025 \\ https://hal-insu.archives-ouvertes.fr/insu-02873025}

Submitted on 24 Jul 2020

HAL is a multi-disciplinary open access archive for the deposit and dissemination of scientific research documents, whether they are published or not. The documents may come from teaching and research institutions in France or abroad, or from public or private research centers.
L'archive ouverte pluridisciplinaire HAL, est destinée au dépôt et à la diffusion de documents scientifiques de niveau recherche, publiés ou non, émanant des établissements d'enseignement et de recherche français ou étrangers, des laboratoires publics ou privés. 
3

4

5

6

7

Annelore Bessat ${ }^{1}$, Thibault Duretz ${ }^{2,1}$, György Hetényi ${ }^{1}$, Sébastien Pilet ${ }^{1}$ and Stefan M. Schmalholz ${ }^{1}$

${ }^{1}$ Institute of Earth Sciences, University of Lausanne, 1015 Lausanne, Switzerland

${ }^{2}$ Univ Rennes, CNRS, Géosciences Rennes - UMR 6118, F-35000 Rennes, France

annelore.bessat@unil.ch

submitted to Geophysical Journal International

Section: Geodynamics and tectonics

Abbreviated title: Stress and deformation mechanisms at subduction zones

This article has been accepted for publication in Geophysical Journal International @: 2020 Bessat, A., Duretz, T., Hetényi, G., Pilet, S., and Schmalholz, S.M. Published by Oxford University Press on behalf of the Royal Astronomical Society. All rights reserved.

This is an authors' pre-print version of this paper. The final version is available here: https://academic.oup.com/gji/advance-article-abstract/doi/10.1093/gji/ggaa092/5743420 or via the DOI https://doi.org/10.1093/gii/ggaa092

\section{Summary}

Numerous processes such as metamorphic reactions, fluid and melt transfer and earthquakes occur at a subducting zone, but are still incompletely understood. These processes are affected, or even controlled, by the magnitude and distribution of stress and deformation mechanism. To eventually understand subduction zone processes, we quantify here stresses and deformation mechanisms in and around a subducting lithosphere, surrounded by asthenosphere and overlain by an overriding plate. 
We use two-dimensional thermo-mechanical numerical simulations based on the finite difference and marker-in-cell method and consider a $3200 \mathrm{~km}$ wide and $660 \mathrm{~km}$ deep numerical domain with a resolution of $1 \mathrm{~km}$ by $1 \mathrm{~km}$. We apply a combined visco-elasto-plastic deformation behaviour using a linear combination of diffusion creep, dislocation creep and Peierls creep for the viscous deformation. We consider two end-member subduction scenarios: forced and free subduction. In the forced scenario, horizontal velocities are applied to the lateral boundaries of the plates during the entire simulation. In the free scenario, we set the horizontal boundary velocities to zero once the subducted slab is long enough to generate a slab pull force large enough to maintain subduction without horizontal boundary velocities. A slab pull of at least $1.8 \mathrm{TN} \mathrm{m}^{-1}$ is required to continue subduction in the free scenario. We also quantify along-profile variations of gravitational potential energy (GPE). We evaluate the contributions of topography and density variations to GPE variations across a subduction system. The GPE variations indicate large-scale horizontal compressive forces around the trench region and extension forces on both sides of the trench region. Corresponding vertically-averaged differential stresses are between 120 and $170 \mathrm{MPa}$. Furthermore, we calculate the distribution of the dominant deformation mechanisms. Elasto-plastic deformation is the dominant mechanism in the upper region of the lithosphere and subducting slab (from ca. 5 to $60 \mathrm{~km}$ depth from the top of the slab). Viscous deformation dominates in the lower region of the lithosphere and in the asthenosphere. Considering elasticity in the calculations has an important impact on the magnitude and distribution of deviatoric stress; hence, simulations with increased shear modulus, in order to reduce elasticity, exhibit considerably different stress fields. Limiting absolute stress magnitudes by decreasing the internal friction angle causes slab detachment so that slab pull cannot be transmitted anymore to the horizontal lithosphere. Applying different boundary conditions shows that forced subduction simulations are stronger affected by the applied boundary conditions than free subduction simulations. We also compare our modelled topography and gravity anomaly with natural data of seafloor bathymetry and free-air gravity anomalies across the Mariana trench. Elasticity and deviatoric 
stress magnitudes of several hundreds of $\mathrm{MPa}$ are required to best fit the natural data. This agreement suggests that the modelled flexural behaviour and density field are compatible with natural data. Moreover, we discuss potential applications of our results to the depth of faulting in a subducting plate and to the generation of petit-spot volcanoes.

\section{Keywords :}

Numerical modelling; Subduction zone processes; Lithospheric flexure; Rheology: mantle; Dynamics: gravity and tectonics

\section{1. - Introduction}

Subduction zones are critical locations on Earth where the oceanic lithosphere dives into the convecting mantle and, hence, contributes to the cooling of the Earth and to the recycling of rocks and water (e.g. Stern, 2002; Turcotte \& Schubert, 2014; Crameri et al., 2019). Many geophysical and geochemical processes are related to subduction zones, such as hydration of the mantle wedge and associated melt generation related to arc magmatism (e.g. Plümper et al., 2016), major earthquakes observed at different depths in the subducting slab and at megathrusts (e.g. Youngs et al., 1997), water transport in subducting slabs along faults (e.g. Faccenda et al., 2009) or the generation of petit-spot volcanoes, which might be associated with plate flexure around subduction zones (Hirano et al., 2006; Yamamoto et al., 2014). However, many of these processes are still incompletely understood. Processes inside and around subducting plates are, to a larger or smaller extent, controlled by the magnitude and the type of stress (extensive, compressive or shear) and by the dominant deformation mechanism (elastic, frictional-plastic or viscous). Since it is not possible to study stress and deformation mechanisms around subduction zones in situ, indirect approaches like geophysical imaging (e.g. Kearey et al., 2009) and numerical modelling in two-dimensions (2D) (e.g. Gurnis et al., 2004; Yamato et al., 2007; Schmeling et al., 2008; Gerya, 2011) and 3D (e.g. Schellart et al., 2007; Yamato et al., 2009; 
Duretz et al., 2014) are frequently used to study subduction systems. Numerical models are suitable to quantify the magnitude of stress and the associated distribution of deformation mechanisms for subduction systems (e.g. Čížková et al., 2007; Garel et al., 2014). A better understanding of the magnitude of stress, their distribution and their associated dominant deformation mechanisms in subduction systems might ultimately help us to understand subduction-related geophysical and geochemical processes.

The main aim of this study is to quantify stresses and to determine the distribution of stress and dominant deformation mechanism around flexural regions in a subducting plate. Although there are numerous studies of numerical subduction simulations, only few numerical models quantified the distribution of stress (e.g. Hassani et al., 1997; Funiciello et al., 2003; Sobolev et al., 2006; Čížková et al., 2007; Babeyko \& Sobolev, 2008; Farrington et al., 2014; Holt et al., 2015) and deformation mechanisms (e.g. Čížková et al., 2007; Garel et al., 2014). Like all models, they have limitations in their hypotheses, such as neglecting elastic deformation (e.g. Čížková et al., 2007; Chertova et al., 2012; Garel et al., 2014; Holt et al., 2015), no or only one creep deformation mechanism (e.g. Hassani et al., 1997; Funiciello et al., 2003; Farrington et al., 2014), a prescribed slab geometry (e.g. Sobolev et al., 2006; Babeyko \& Sobolev, 2008), no free surface boundary condition (e.g. Čižková et al., 2007; Holt et al., 2015) or a yield stress being a function of depth only (e.g. Čižková et al., 2007; Garel et al., 2014) and not a function of the total pressure (negative mean stress). Here, we build on the above mentioned models, but without the mentioned limitations with the aim to make a step further in calculating stress and dominant deformation mechanisms at subduction systems. We apply a high-resolution $(1 \mathrm{~km}$ grid spacing) 2D thermo-mechanical numerical model of the lithosphere-asthenosphere system and we consider five deformation mechanisms: elastic, frictional-plastic (Mohr-Coulomb criterion), diffusion creep, dislocation creep and Peierls creep. We apply a local iteration strategy to correctly calculate the partitioning of the strain rate between these five deformation mechanisms, because calculations without such iterations overestimate the calculated stress (Schmalholz \& Duretz, 2017). Furthermore, 
we consider two subduction scenarios, which represent two end-member conditions with respect to the forces driving subduction: (1) forced subduction whereby the subducting plate is pushed by farfield horizontal velocity (e.g., by ridge push), and (2) free subduction whereby subduction is driven only by the negative buoyancy of the subducting plate itself (slab pull). We initiate free subduction by forced subduction but set the far-field velocity to zero once slab pull is large enough to drive free subduction. We quantify the required minimum slab pull force to drive free subduction for our model configuration. We also quantify along-profile variations of gravitational potential energy (e.g., Molnar \& Lyon-Caen, 1988; Molnar et al., 1993; Schmalholz et al., 2014; Schmalholz et al., 2019) across the subduction system, because these GPE variations cause horizontal forces and, hence, stresses. We also investigate whether differentiating criteria between forced and free subduction exist and what these criteria are. Furthermore, we evaluate the impact of elasticity and yield stress on the deformation and stress field around subduction zones. We do not configure our model to fit a particular subduction system, but in order to evaluate whether the modelled subductions are applicable to natural subduction zones, we finally compare the modelled topography and gravity anomalies with natural data from the Mariana subduction zone, which is a type-example for an ocean-ocean subduction system and has often been used for comparison with theoretical models (e.g., Funiciello et al., 2003; Turcotte \& Schubert, 2014).

\section{2. - Mathematical model}

\subsection{Governing equations for numerical simulations}

We use the 2D thermo-mechanical code MDoodz, which is based on the finite difference and markerin-cell method (e.g. Duretz et al. 2011b; Gerya, 2019). The steady-state force balance equation is

$$
\frac{\partial \sigma_{i j}}{\partial x_{j}}+\rho g_{i}=0
$$


where $i$ and $j$ run from 1 to 2, 1 indicates horizontal and 2 vertical dimension, $\sigma_{i j}$ are the components of the total stress tensor, $x_{j}$ represents the spatial coordinates, $\rho$ is the density and $g_{i}=[0,-g]$ is the gravitational acceleration vector with $g$ being the gravitational acceleration. The conservation of mass for incompressible material is

$$
\frac{\partial v_{i}}{\partial x_{i}}=0
$$

where $v_{i}$ are the components of the velocity vector. The temperature evolution equation is

$$
\rho c \frac{\mathrm{d} T}{\mathrm{~d} t}=\frac{\partial}{\partial x_{i}}\left(k \frac{\partial T}{\partial x_{i}}\right)+H_{D}+H_{R}
$$

where $d / d t$ represents the total time derivative, $c$ the specific heat, $k$ the thermal conductivity, $H_{R}$ the radiogenic heat production and $H_{D}$ the heating due to viscous and plastic dissipative work (here we assume that all dissipative work is converted into heat, i.e., Taylor-Quinney coefficient is 1 , since we do not model grain size reduction).

The density is calculated with the following equation of state:

$$
\rho=\rho_{0}\left[1+\beta\left(P-P_{0}\right)\right] *\left[1-\alpha\left(T-T_{0}\right)\right]
$$

where $\rho_{0}$ is the reference density at a reference pressure $P_{0}$ and temperature $T_{0}, P$ is the pressure (negative mean stress), $T$ is the temperature, $\alpha$ is the thermal expansion and $\beta$ is the compressibility. The components of the total stress tensor are

$$
\sigma_{i j}=-P \delta_{i j}+\tau_{i j}
$$

where $\delta_{i j}$ is the Kronecker delta $\left(\delta_{i j}=1\right.$ when $i=j$ and $\delta_{i j}=0$ when $\left.i \neq j\right)$ and $\tau_{i j}$ are the components of the deviatoric stress tensor. We consider a visco-elasto-plastic rheology described by a Maxwell model (Moresi et al., 2003; Popov \& Sobolev, 2008):

$$
\dot{\varepsilon}_{i j}=\dot{\varepsilon}_{i j}^{\mathrm{vis}}+\dot{\varepsilon}_{i j}^{\mathrm{el}}+\dot{\varepsilon}_{i j}^{p l}=\frac{1}{2 \eta} \tau_{i j}+\frac{1}{2 G} \frac{D \tau_{i j}}{D t}+\dot{\gamma} \frac{\partial Q}{\partial \tau_{i j}}
$$

where superscripts $\dot{\varepsilon}_{i j}^{\mathrm{vis}}, \dot{\varepsilon}_{i j}^{\mathrm{el}}$ and $\dot{\varepsilon}_{i j}^{\mathrm{pl}}$ indicate viscous, elastic and plastic deviatoric strain rate tensors, respectively. The quantity $\eta$ represents the effective viscosity, $G$ is the shear modulus, $t$ is the time, 
$D / D t$ indicates the objective time derivative (e.g., Schmalholz et al., 2001), $Q$ is the plastic flow potential and $\dot{\gamma}$ is a plastic multiplier rate.

Frictional-plastic yielding is described by a Drucker-Prager criterion with the yield stress, $\tau_{\text {yield }}$

$$
\tau_{\text {yield }}=C \cos (\Theta)+P \sin (\Theta)
$$

142 where $C$ is the cohesion and $\Theta$ is the angle of internal friction. The yield function, $F$, is expressed as $F=\tau_{\text {II }}-\tau_{\text {yield }}$ and the plastic potential is formulated as $Q=\tau_{\text {II }}$, being the square root of the second invariant of the deviatoric stress tensor. Plastic deformation occurs whenever $F \geq 0$. The 145 plastic multiplier rate is computed as $\dot{\gamma}=2 \dot{\varepsilon}_{I I}-\frac{\tau_{\text {yield }-\tau_{\text {II }} \text { old }}}{G \mathrm{~d} t}+\frac{\tau_{\text {yield }}}{\eta}$ or simply $\dot{\gamma}=\frac{F}{\eta^{\mathrm{ve}^{\mathrm{e}}}}$, where $\eta^{\mathrm{ve}}=$ $146\left(\frac{1}{\eta}+\frac{1}{G \mathrm{~d} t}\right)^{-1}, \tau_{i j}$ old are advected and rotated stress components from the previous time step and $\mathrm{d} t$ 147 is the time step. Subsequently, the plastic strain rate tensor is evaluated as $\dot{\varepsilon}_{i j}^{\mathrm{pl}}=\dot{\gamma} \frac{\partial Q}{\partial \tau_{i j}}=\dot{\gamma} \frac{\tau_{i j}}{2 \tau_{\mathrm{II}}}$. In practice, the stress state is mapped back onto the yield surface by modifying the effective viscosity as:

$$
\eta=\eta^{\mathrm{pl}}=\frac{\tau_{\text {yield }}}{2 \dot{\varepsilon}_{\mathrm{II}}^{\mathrm{eff}}}
$$

where $\dot{\varepsilon}_{\mathrm{II}}^{\mathrm{eff}}$ is the square root of the second invariant of the effective strain rate tensor, defined as

$$
\dot{\varepsilon}_{i j}^{\text {eff }}=\dot{\varepsilon}_{i j}+\frac{\tau_{i j}{ }^{\text {old }}}{2 G \mathrm{~d} t}
$$

151 The viscous deformation is a linear combination of flow laws for diffusion creep (Hirth \& Kohlstedt, 2003), dislocation creep (Hirth \& Kohlstedt, 2003) and Peierls creep (Kameyama et al., 1999):

$$
\dot{\varepsilon}_{i j}^{\mathrm{vis}}=\dot{\varepsilon}_{i j}^{\mathrm{dif}}+\dot{\varepsilon}_{i j}^{\mathrm{dis}}+\dot{\varepsilon}_{i j}^{\text {pei }}
$$

153

154

Diffusion creep (i.e., linear creep) is given by

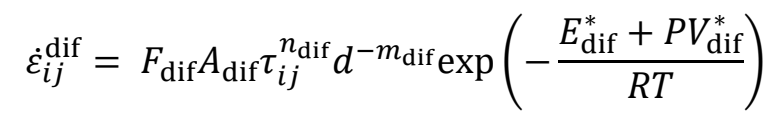




$$
\dot{\varepsilon}_{i j}^{\mathrm{dis}}=F_{\mathrm{dis}} A_{\mathrm{dis}} \tau_{i j}^{n_{\mathrm{dis}}} d^{-m_{\mathrm{dis}}} \exp \left(-\frac{E_{\mathrm{dis}}^{*}+P V_{\mathrm{dis}}^{*}}{R T}\right)
$$

156

Peierls creep (i.e., low-temperature plasticity or exponential creep) is given by

$$
\dot{\varepsilon}_{i j}^{\text {pei }}=F_{\text {pei }} A_{\text {pei }} \exp \left[-\frac{E_{\text {pei }}}{R T}(1-\gamma)^{n_{\text {pei }}}\right]\left(\frac{\tau_{i j}}{\gamma \sigma_{\text {pei }}}\right)^{S}
$$

157

with

$$
S=\frac{E_{\mathrm{pei}}}{R T}(1-\gamma)^{\left(n_{\mathrm{pei}}-1\right)} n_{\mathrm{pei}} \gamma
$$

158

159

160

161

In the above flow laws, $F$ is a transformation factor to transform flow laws fitted form rock deformation data to flow laws for tensor components (e.g., Schmalholz \& Fletcher, 2011; Gerya, 2019), $A$ is a material constant determined from laboratory measurements, $n$ is the stress exponent, $d$ is the grain size, $m$ is the grain size exponent, $E$ is the activation energy, $V$ is the activation volume, $R$ is the gas constant, $\gamma$ is an adjustable constant (Kameyama et al., 1999) and $\sigma_{\text {pei }}$ is the Peierls stress (see values in Table 1).

Due to the occurrence of non-Newtonian creep mechanisms, Equation (6) is generally non-linear. We thus employ a local iteration method (Popov \& Sobolev, 2008; Schmalholz \& Duretz, 2017) that ensures correct additive decomposition of the strain rate tensor and computation of stress tensor.The resulting effective viscosity for dissipative deformation mechanism is equal to the pseudo-harmonic mean of the viscosities of each dissipative deformation mechanism:

$$
\eta=\left(\frac{1}{\eta^{\text {dis }}}+\frac{1}{\eta^{\text {dif }}}+\frac{1}{\eta^{\text {pei }}}+\frac{1}{\eta^{\text {pl }}}\right)^{-1}
$$

where $\eta^{\text {dis }}, \eta^{\text {dif }}, \eta^{\text {pei }}$ and $\eta^{\text {pl }}$ are the effective viscosities calculated with the corresponding second invariant of strain rate tensor for each deformation mechanism for the viscous and the plastic deformations. In the performed simulations, we apply a minimum cut-off of the viscosity at $10^{19} \mathrm{~Pa} \cdot \mathrm{s}$ and a maximum cut-off at $10^{25} \mathrm{~Pa} \cdot \mathrm{s}$, allowing for viscosities in the models with six orders of magnitude difference. 
The applied method allows to calculate iteratively the individual strain rates of each deformation mechanism at a given temperature and total strain rate. Figures $1 a-d$ shows the individual strain rates of each dissipative deformation mechanism, a) dislocation, b) diffusion, c) Peierls creep and d) frictional-plasticity in a temperature versus total strain rate space. We perform these calculations for a temperature range of $300^{\circ} \mathrm{C}$ to $1^{\prime} 800^{\circ} \mathrm{C}$ and a total strain rate ranging from $10^{5}$ to $10^{-50}[1 / \mathrm{s}]$ assuming a constant pressure of $1 \mathrm{GPa}$. Several mechanisms can be active simultaneously (Fig. 1). For illustrative purposes, we apply here a stress of $500 \mathrm{MPa}$ to indicate the limit between the frictional-plastic and viscous domains. In the 2D numerical simulations, the plastic yield stress is pressure-sensitive and varies in space and time. To visualize the dominant deformation mechanism, we compare at each point in the strain rate versus temperature domain the four individual strain rates and identify which mechanism provides the highest strain rate. The mechanism associated with the largest strain rate is the dominant mechanism, as shown in the dominant deformation mechanism map displayed in Figure 1e. Diffusion creep is the dominant mechanism at high temperatures for low strain rates (in orange). Dislocation creep is dominant at high temperatures and higher strain rates (in red). Peierls creep is dominant at low temperature and moderate strain rates (in dark blue) and the plastic domain is dominant at low temperature and high strain rates (in light blue).

\subsection{Calculation of slab pull and gravitational potential energy}

We quantify two types of forces around subduction zones, one resulting from slab pull force and one resulting from spatial variations of the gravitational potential energy.

We calculate the slab pull force (per unit length) through time with the following integral for a specific time step (approximated by a sum for the numerical calculation):

$$
\vec{F}_{\mathrm{SP}}=\int_{H_{\mathrm{Sb}}}^{H_{\mathrm{LAB}}} \Delta \rho g d V \approx \sum \Delta \rho g d x d z n^{\text {lith }}
$$

where $\Delta \rho$ is the density difference between the density at each point (either the density of the lithosphere or the density of the asthenosphere) and the reference density depth profile on the left 
side of the model, and $d x$ and $d z$ are the numerical grid spacings, respectively. We calculate the slab pull only in the asthenosphere, between the bottom of the model $\left(H_{\mathrm{sb}}\right)$ and the initial depth of the lithosphere-asthenosphere boundary $\left(H_{\mathrm{LAB}}\right)$. We consider only numerical cells that include lithospheric material for the calculation of the slab pull force by using the integer $n^{\text {lith }}$, which is 1 for cells including lithospheric material and 0 otherwise.

The gravitational potential energy per unit area (GPE) corresponds to the depth-integrated lithostatic pressure $P_{L}\left[N / m^{2}\right]$, which is calculated as

$$
P_{\mathrm{L}}(x, z)=\int_{z}^{S t(x)} \rho\left(x, z^{\prime}\right) g d z^{\prime}
$$

The GPE is then

$$
G P E(x)=\int_{S b}^{S t(x)} P_{\mathrm{L}}(x, z) d z+\text { const }
$$

where $S t(x)$ is the topography of the model which can vary in the horizontal $(x)$ direction, $z$ is the depth and $S b$ is the base of the model (for details see Schmalholz et al., 2014). To calculate the topography in our simulations, we apply a numerical algorithm, which includes an Eulerian-Lagrangian free surface implementation, which allows resolving topographic variations at the sub-grid level (Duretz et al., 2016).

The along-profile variation of GPE, $\triangle G P E$, is calculated by subtracting a reference GPE value from all other values. We choose here the GPE value on the left model side as reference value. Along-profile variation of $\triangle G P E$ can be due to a horizontal variation of density or a variation of the topography. The $\triangle G P E$ provides an estimate for the horizontal driving force per unit length (e.g., Molnar \& Lyon-Caen, 1988; Schmalholz et al., 2014; Schmalholz et al., 2019) in the subduction system associated to the density variation at depth due to subduction and to the associated spatial variation of topography. Regions with a negative $\triangle G P E$ are under compression and regions with a positive $\triangle G P E$ are under extension. 


\subsection{Configuration of the thermo-mechanical models}

221

The size of the model domain is $3200 \mathrm{~km}$ in width and $660 \mathrm{~km}$ in height with a numerical resolution of $1 \mathrm{~km}$ by $1 \mathrm{~km}$, yielding 2.112 million cells. The time step is calculated according to a Courant criterion of 0.4 in the model. We fixed the initial thickness of the lithosphere to $80 \mathrm{~km}$ following the seismic study from Kawakatsu et al. (2009) which localized the lithosphere-asthenosphere boundary (LAB) at this depth for the Pacific lithosphere subducting below Japan. A $5 \mathrm{~km}$ thick layer of weak material (cohesion of $1 \cdot 10^{6} \mathrm{~Pa}$ and internal friction angle of $0^{\circ}$; see Table 1 ) is placed on the top of the lithosphere to mimic weak hydrated crust (Crameri et al., 2012). The main aim of this modelling study is to quantify stresses and determine dominant deformation mechanisms in flexural lithospheric regions. Therefore, we apply a simple density and temperature model for the sub-lithospheric region. Initially, the temperature of the asthenospheric mantle $\left(T_{\text {ast }}\right)$ is homogeneous and for simplicity fixed at $1^{\prime} 450^{\circ} \mathrm{C}$. For the temperature of the lithospheric mantle, we consider also for simplicity a linear gradient from $0^{\circ} \mathrm{C}$ at the surface to the temperature of the asthenospheric mantle ( $\left.T_{\text {ast }}\right)$ at the LAB ( 80 $\mathrm{km}$ depth). The initiation of subduction was facilitated by prescribing an oblique weak zone with an initial thickness of $10 \mathrm{~km}$ in the horizontal middle of the model (Fig. 2b). The weak zone is characterized by a low plastic strength (see Equation 7 and Table 1) and has the same properties as the weak upper layer.

We use dry olivine for the viscous flow laws of the lithosphere and asthenosphere with the rheological parameters reported in Table 1 (Hirth \& Kohlstedt, 2003; Goetze \& Evans, 1979 regularized by Kameyama et al., 1999). We employ the dry olivine flow law because the weaker wet olivine is commonly too weak in numerical subduction models and does not generate a coherent slab, but rather generates the dripping of the mantle lithosphere (e.g., Burov, 2010).

We consider two end-member subduction configurations to compare the stress and deformation mechanism in forced and free subduction models. In the forced subduction model, subduction is driven 
by a horizontal velocity acting at the sides of the lithosphere. Therefore, the slab velocity is controlled by the applied boundary velocity. In contrast, subduction is only driven by the negative buoyancy of the dense lithosphere in a free subduction model. Therefore, the slab velocity can evolve freely and is controlled by the interaction of buoyancy, flexural and viscous resistance stresses in and around the slab. In the forced subduction model, we apply a symmetrical horizontal velocity on the lithosphere at both sides of the model (Fig. 2b). We choose symmetrical boundary conditions (Chertova, 2012) to have a straight slab as imaged in Japan with tomography (Liu \& Zhao, 2016). The total convergence velocity is $10 \mathrm{~cm} \cdot \mathrm{yr}^{-1}$, as observed in Japan for the Pacific plate (Gripp \& Gordon, 1990). These velocity profiles are implemented by specifying a material in-flux in the top part of the model sides until a depth of twice the thickness of the lithosphere. To ensure conservation of the mass, an equivalent out-flux is applied in the lower part of the model sides (Fig. 2b). For the boundary conditions, we use free slip at the model bottom and specific velocity profiles at the left and right model sides (Fig. 2b). At the top of the crust we use a free surface boundary condition (Duretz et al., 2016; Fig. 2b), because previous numerical studies show that the surface topography is controlled by the geometry, rheology and density of the slab (e.g. Zhong \& Gurnis, 1994) and that a free surface condition is required to calculate realistic stresses in subducting slabs (Crameri et al., 2017). For our model configuration (Fig. 2b), subduction will not initiate without horizontal boundary velocities, because there is initially no slab and, hence, no slab pull. Therefore, we initiate subduction in all the simulations with a weak zone in the lithosphere and with external velocities compressing the lithosphere (e.g. Toth \& Gurnis, 1998). This model scenario is comparable to the compression-induced mode according to the classification of subduction initiation modes of Stern \& Gerya (2018). To initiate free subduction, we first impose boundary velocities and then set the boundary velocities to zero once the slab is large enough to drive subduction without imposed boundary velocities. To constrain the moment when slab pull forces are sufficient to drive subduction, we perform several simulations in which we set the boundary velocities to zero after different simulation times (Fig. 2c), implying the 
absence of material flux across lateral boundaries. We also include a weak domain ( $30 \mathrm{~km}$ thick) adjacent to right model boundary, which decouples the lithosphere from the lateral boundary and avoids prescribing a slab-retreat dominated subduction (Fig. 2c). To determine the conditions required for free subduction development, we start the model with forced subduction, save the configuration at different times (Fig. 2a) and then use the saved configurations in the free subduction model to evaluate whether subduction continues or not.

To test the impact of the applied boundary conditions, we also performed two simulations with different boundary conditions: one forced subduction simulation for which the horizontal velocity is only applied at the right model side and one free subduction simulation for which we add a weak zone at both lateral model sides. An overview of the performed simulations is given in Table 2 .

\subsection{Configuration for the gravity anomaly calculations}

With the simulation results we also compute synthetic gravity anomalies in order to compare them with real data, in particular across the Mariana trench. For the gravity anomaly calculations, we use the algorithm of Won \& Bevis (1987), based on the method of Talwani et al. (1959). The calculation uses the model geometry and corresponding density field of the numerical mesh at the final time step. To avoid edge effects, the model sides have been extended to great distances ( $10^{\prime} 000 \mathrm{~km}$ each side), which ensures the far-field fit of the gravity field. The topography in our model corresponds to the seafloor, therefore, we add a water layer of $5 \mathrm{~km}$ thickness with respect to the far-field, undeformed seafloor with a density of $1^{\prime} 000 \mathrm{~kg} \cdot \mathrm{m}^{-3}$. We then calculate the gravity contribution of all numerical elements at virtual measurement stations (10 km spacing) at sea-level to obtain a synthetic free-air anomaly profile, which can be then compared to the anomaly profile obtained from natural data. 


\section{4. - Results}

We performed nine simulations whose characteristics and differences are listed in Table 2. We employed the colour-maps "lapaz" and "vik" of Crameri (2018) for the visualization.

\section{1. - Quantification of slab pull force and gravitational potential energy}

We first compare three different simulations (Fig. 3) using identical material parameters, namely simulation S0 for forced subduction scenario (Figs. 3a-c) and simulations S1 and S2 for free subduction scenarios (Figs. 3d-i). The only difference between S1 and S2 is the time at which we set the horizontal boundary velocities to zero. The time at which free subduction starts is termed $t_{\text {free }}$ and it is equal to 1.25 Ma in S1 and 1.17 Ma in S2. In S0 (Figs. 3a-c), subduction develops with a relative retreat of the trench to the right of the model. This retreat is caused by the velocity imposed on the left side of the box. This trench retreat is not observed in S1 and S2 because no more lithosphere is created on the left side of the box due to the change of boundary conditions (Figs. $3 \mathrm{~d}-\mathrm{i}$ ). The evolution of slab geometry differs between models S0 and S1. At the beginning of the simulations (Figs. 3a and d) slabs are similar in both models. The time of these two panels (Figs. 3a and d) is not identical because for S1 we display the first time step of the free subduction simulation, which has a different numerical time step (due to the Courant criterion which is velocity dependent) than the forced subduction simulation. With progressive time, the dip and curvature of the slabs evolve differently. SO shows a more straight and vertical slab with a smaller curvature in the deeper regions, while S1 shows a slab dip in the opposite direction than the one in the shallower region (Fig. 3f). This curl-type motion is associated with the configuration of the free subduction model, which requires the asthenospheric material to fill the region of the detached slab at the top right region of the model.

Figures $3 g-i$ shows a scenario of a failed model of free subduction development (S2). The only difference between $\mathrm{S} 1$ and $\mathrm{S} 2$ is the time at which the horizontal boundary velocities are set to zero ( $\left.t_{\text {free}}\right)$. These simulations show that the difference between a successful or failed free subduction simulation is linked to the slab pull force, associated only to the negative buoyancy of the slab after 
$t_{\text {free. }}$ To determine the slab pull force required to develop a free subduction in our model configuration and to evaluate the impact of rheological parameters, we first calculate the slab pull force for three different forced subduction simulations (Fig. 4b), namely S0, S4 and S5 (Table 2). In S4 we increased the shear modulus to $G=3 \cdot 10^{13} \mathrm{~Pa}$, in order to decrease the impact of elasticity, and in S5 we reduced the friction angle to $5^{\circ}$. The three simulations show a similar increase of the slab pull force as function of time up to ca. $4 \mathrm{Ma}$ (Fig. 4b). After $4 \mathrm{Ma}$, S5 differs from the other two simulations and shows a larger slab pull for the same time. We apply several free subduction starting times ( $t_{\text {free }}$ corresponding to squares and circles in Fig. 4a) for the reference forced subduction simulation S0 in order to evaluate the required slab pull force for free subduction (Fig. 4a). For the applied model configuration, a slab pull force larger than $1.8 \mathrm{TN} \cdot \mathrm{m}^{-1}$ is required to develop a free subduction in the case of SO. The time to generate this slab pull force in S0 is ca. $1.15 \mathrm{Ma}$ using a horizontal boundary velocity of $5 \mathrm{~cm} \cdot \mathrm{yr}^{-1}$ at each side of the model. If the slab pull is not large enough before the horizontal boundary velocities are set to zero, then the subduction slows down and ceases, temperature conduction heats up the slab, as illustrated by the shift of the isotherm for $1^{\prime} 440^{\circ} \mathrm{C}$ in the asthenosphere (Fig. $3 \mathrm{~h}$ ), and the base of the lithosphere starts to delaminate. In contrast, when slab pull is larger than $1.9 \mathrm{TN} \cdot \mathrm{m}^{-1}$ in S0, the subduction continues. The vertical velocities associated with the delamination for a failed free subduction model are significantly slower than velocities of the subducting slab (compare times in Figs. 3c, f and i).

The quantification of along-profile variations of GPE, $\triangle G P E$, in the lithosphere-asthenosphere system allows quantifying the along-profile variation of horizontal driving forces in the system. Hence, regions under overall horizontal compression or extension are identified and the corresponding horizontal forces are quantified. To investigate these forces around the modelled subduction system, we quantify the relative contribution of (i) density variations below the initial lithospheric thickness due to subduction and (ii) topography variations due to lithospheric flexure to $\triangle G P E$. To quantify contributions due to sub-lithospheric density variations we calculate $\triangle G P E$ by integrating $P_{\mathrm{L}}$ from the 
model bottom up to a depth of $80 \mathrm{~km}$, the initial lithosphere thickness. The relative variation of the total $\triangle G P E$ and the topography agree in the right side of the subduction trench for both forced and free subduction model (Figs. 5 and 6). This agreement indicates that the variation of total $\triangle G P E$ is controlled by the variation of topography created by the flexure of the lithosphere, and that the flexure of the subducting plate does not affect the density field below the lithosphere. In contrast, relative variations of total $\triangle G P E$ and the topography on the upper plate side of the trench do not agree. If a significant slab has developed, then the variation of total $\triangle G P E$ on the upper plate side of the trench agrees with the $\triangle G P E$ beneath $80 \mathrm{~km}$ because the variation in total $\triangle G P E$ is there controlled by deep density variations due to subduction of the cold slab. The GPE calculation shows that the subduction system is characterized by three regions with respect to $\triangle G P E$ variations and associated horizontal driving forces: (1) extensional horizontal driving forces related to the flexural bulge of the subducting plate, (2) compressive horizontal driving forces in the trench region associated to the negative topography of the trench region and (3) extensional horizontal driving forces in the overriding plate region related to deep density variations caused by the subducted plate (Figs. 5 and 6). The maximal difference in total GPE for the forced subduction is ca. $80 \mathrm{TN} / \mathrm{m}$ and for the free subduction ca. 110 TN. $\mathrm{m}^{-1}$ (Fig. $5 \mathrm{c}$ and $6 \mathrm{c}$ ). The division of these values by the model height of $660 \mathrm{~km}$ provides a minimum estimate for the vertical average of the horizontal differential stress caused by subduction-related variations of GPE. These vertically-averaged horizontal differential stresses are ca. $121 \mathrm{MPa}$ and 167 MPa for the forced and free subduction, respectively. These vertically-averaged differential stresses are required to maintain the subduction zone and to avoid that the subduction system disappears immediately and returns to a state of static equilibrium, which is characterised by vertical density variations only and no topography. 
We quantify the strain rate field with the square root of the second invariant of the deviatoric strain rate tensor, $\dot{\varepsilon}_{I I}$, for the forced (Figs. 7a-c, S0) and the free subduction model (Figs. 7d-f, S1). High values of $\dot{\varepsilon}_{I I}$ indicate regions of intense deformation whereas low values indicate regions of little deformation. The distribution and magnitude of $\dot{\varepsilon}_{I I}$, hence, indicates, for example, whether the deformation around a subduction system and within the slab is either more or less homogeneous or strongly heterogeneous. For both $\mathrm{S} 0$ and $\mathrm{S} 1$ the strain rates in the upper region of the lithosphere are small away from the subduction zone (Fig. 7). These low strain rate regions feature high viscosity, dominantly elastic deformation (see following sections, Figs. 9 and 10) and an essentially rigid, plate-like behaviour. In SO, strain rates are generally highest in the lower region of the lithosphere and in the upper regions of the asthenosphere (Figs. 7a-c). These high strain rates are due to the applied horizontal boundary velocity profile, which move material into the model domain in the upper model region and, to conserve mass, move material out of the model in the lower regions (see Fig. 2b). For S1, the strain rates in the upper plate region, in the front of the subducting slab, are significantly smaller because no material in- and out-flow is considered (Figs 7d-f). However, strain rates are also high in the lower regions of the subducting plate (right model region) where the underlying asthenosphere is being sheared by the subducting plate (Figs. 7d-f).

To study the relative importance of the five modelled deformation mechanisms, namely elastic deformation, frictional-plastic deformation, diffusion creep, dislocation creep, and Peierls creep we plot the individual strain rates for each deformation mechanism separately using Equation (6) (Fig. 8). Figure 8a shows the total strain rate corresponding to the results shown in Figure 7c for S0. Strain rates due to elastic deformation are significant in the upper regions of the lithosphere in the subduction 
zone (Fig. 8b). Strain rates due to frictional-plastic deformation are significant (i) in the weak zone between the overriding and subducting plate and (ii) in the uppermost region of the subducting plate where the plate starts to subduct (Fig. 8c). This region corresponds to the outer hinge zone of the subducting plate. In the lower region of the lithosphere and upper region of the asthenosphere, both diffusion and dislocation creep are significant (Figs. 8d and e). Strain rates due to dislocation creep are generally higher than the ones for diffusion creep. High strain rates due to dislocation creep are in the mantle lithosphere and in the mantle wedge corner (Fig. 8e). Strain rates caused by Peierls creep are significant only (i) in small areas in the region where the plate subducts and (ii) in a small area around the hinge region of the subducting plate (Fig. 8f). Around the subduction zone, each of the five deformation mechanisms is dominant in some region (Fig. 8g). Therefore, all five deformation mechanisms are important for lithosphere deformation around the subduction zone. For comparison, the corresponding effective viscosity field is also shown (Fig. 8h). Upper regions of the lithosphere with high effective viscosity correspond generally to regions in which elastic deformation is dominant. Low viscosity regions correspond to regions in which dislocation and diffusion creep is dominant. Considering the entire model domain, the distribution of dominant deformation mechanism is similar for S0 and S1 (Fig. 9) except for dislocation creep. The deformation associated with dislocation creep corresponds to the region with the highest strain rate in Fig. 7. Frictional-plastic deformation is dominant in three different regions: in a thin zone (ca. $5 \mathrm{~km}$ thick) on the top of the lithosphere corresponding to the model weak crust, in the triangular weak zone mimicking an accretionary prism between the subducting and overriding plates, and in the outer hinge zone caused by flexure of the downgoing slab. In this hinge zone, frictional-plastic deformation associated with the development of normal-fault-type shear zones propagates downwards to ca. $30 \mathrm{~km}$ depth. Elastic deformation is 412 dominant in the upper regions of the lithosphere down to a depth of ca. $60 \mathrm{~km}$, measured orthogonally 413 from the top of the lithosphere. Elastic deformation is dominant in the subducting slab to depths of 414 more than $500 \mathrm{~km}$ (Figs 9c and f). 


\section{Effective viscosity}

417 The effective viscosity has contributions from all the considered viscous and plastic deformation 418 mechanisms and thus depends on the strain rate, temperature and pressure. Since these quantities 419 vary in space and time, it is not trivial to predict lithospheric regions, which are mechanically strong or 420 weak, or to predict the absolute values of the effective viscosity. In our simulations, the effective 421 viscosity varies by six orders of magnitude (Fig. 10). The viscosity below the lithosphere, in regions

422 unaffected by the subducted slab, exhibits an increase as function of increasing pressure with depth. This increase from ca. $10^{19}$ to $10^{22} \mathrm{~Pa} \cdot \mathrm{s}$ at the base of the model is due to the increase of pressure with depth controlled by the activation volume, $V$ (Table 1 ). Overall, the effective viscosity distribution is similar for S0 and S1.

\section{Horizontal deviatoric stress}

To identify regions in horizontal compression or extension and to quantify stress magnitudes we analyse the distribution of the horizontal deviatoric stress, $\tau_{x x}$. The bending of the slab around the subduction zone causes flexural stresses and this bending also generates a topographic high, the socalled flexural fore-bulge, in the slab region in front of the subduction zone (e.g., Turcotte and Schubert, 2014). Therefore, we also analyse in the following this topographic bulge to assess how much topographic variation is associated with the calculated stress distribution and magnitudes. The link between surface topography and rheological behaviour of the subducting slab has been also demonstrated by previous studies (e.g., Zhong \& Gurnis, 1994; Crameri et al., 2017). Absolute values of $\tau_{x x}$ are largest in the upper part of the lithosphere where the subducting lithosphere is bending and is colder (Fig. 11). During the initial stages of subduction, both SO and S1 show the characteristic pattern of bending (e.g. Burov, 2011; his figure 5), or flexure, around the hinge zone of the subducting plate (Figs. 11a and d). The outer hinge region is under extension (positive $\tau_{x x}$ ) and the inner hinge 
region is under compression (negative $\tau_{x x}$ ). When subduction evolves and slabs become longer, the plate straightens back, or unbends, causing a stress pattern in the opposite sense (Figs. 11c and f; e.g. Faccenda et al., 2012): the upper part of the lithosphere is under compression and the lower part under extension.

In S0, the horizontal regions of the subducting plate are under compression during the initial stages of subduction (Fig. 11a). With progressive subduction, the stress state of the horizontal region changes from compression to extension and extensive values of $\tau_{x x}$ become larger with progressive subduction (Figs. $11 \mathrm{~b}$ and c). This change in stress state is likely due to the increasing slab pull, which starts pulling the subducting plate once it is larger than the compressive stresses due to the applied boundary velocities. The orientation and magnitude of the principal stresses, $\sigma_{1}$ and $\sigma_{3}$, confirm the result of distribution of $\tau_{x x}$ (Figs. $11 \mathrm{~g}$ and $\mathrm{h}$ ). If the horizontal regions of the lithosphere are in compression, then $\sigma_{1}$ is approximately horizontal (Fig. 11g). For extension, $\sigma_{3}$ is horizontal. The orientation of the principal stresses shows that these principal stresses are always either parallel or orthogonal to the local dip of the subducting plate so that the strong regions of the slab act as a stress guide (Figs. $11 \mathrm{~g}$ and h).

\section{Impact of elasticity}

457

Rocks generally deform visco-elastically, and the time scale over which elastic stresses are relaxed can be estimated to the first order by the so-called Maxwell relaxation time, which is the ratio of the effective viscosity to the shear modulus, $\eta / G$. Using $10^{23} \mathrm{~Pa} \cdot \mathrm{s}$ as representative, average effective viscosity for the slab and $3 \cdot 10^{10} \mathrm{~Pa}$ for $\mathrm{G}$ provides a relaxation time of ca. $100 \mathrm{kyr}$. One could, therefore, argue that elastic stresses are largely relaxed during subduction processes with durations of several millions of years and that, hence, elasticity might not be important for slab deformation during subduction (e.g., Schmeling et al., 2008). To study the impact of elasticity in our models, we performed two forced subduction simulations: one with a shear modulus, $G$ in Equation (6), which is two orders 
of magnitude larger than in the reference simulation, i.e. $3 \cdot 10^{12} \mathrm{~Pa}$, and one with a shear modulus, which is three orders of magnitude larger than in the reference simulation, i.e. $3 \cdot 10^{13} \mathrm{~Pa}$ (Fig. 12). In the simulations with unrealistically high shear modulus of $3 \cdot 10^{12}$ and $3 \cdot 10^{13} \mathrm{~Pa}$ the elastic behaviour is significantly less dominant because the Maxwell relaxation time, during which elastic stresses relax, is significantly shorter (e.g., Jaquet et al., 2016).

We compare the topography of the subducting plate from the three numerical simulations with the analytically calculated flexural geometry fitting the Mariana trench (Turcotte \& Schubert, 2014) and obtain reasonable agreement (Fig. 12a). However, the height of the flexural bulge, ca. $800 \mathrm{~m}$, is higher in the reference simulation than in the simulations with $G=3 \cdot 10^{12} \mathrm{~Pa}$ and $G=3 \cdot 10^{13} \mathrm{~Pa}$, ca. $400 \mathrm{~m}$. The lateral topographic variation around the bulge region is considerably smaller in the simulations with unrealistically high values of $G$, indicating that elasticity has a strong impact on the flexural behaviour in the bulge region. The depth of the trench is similar for the three simulations.

The overall distribution of the horizontal deviatoric stress, $\tau_{x x}$, in the subducting plate is similar for the three simulations (Fig. $12 \mathrm{~b}$ to d). However, the absolute values of $\tau_{x x}$ are smallest for the reference simulation and the reduction of the impact of elasticity increases stress values (Figs. 12b-d). In the simulation with $G=3 \cdot 10^{13} \mathrm{~Pa}$, the overriding plate exhibits significant larger compressive stresses than in the simulation with a standard elastic shear modulus. The regions dominated by elastic deformation are replaced mostly by the frictional-plastic deformation mechanism when the impact of elasticity is reduced (Figs. 12e-g), except in the deeper regions of the subducting lithosphere where elastic deformation is replaced by Peierls creep (Figs. 12e-g). The results show that the implementation of elasticity significantly affects both the magnitude of stresses and the distribution of non-elastic deformation mechanisms. 
489

490

491

492

The absolute magnitudes of stress, especially maximal values, in the mantle lithosphere are still contentious. One reason for this is that different laboratory flow laws for mantle rocks predict stresses that can be up to one order of magnitude different for the same temperature, strain rate and pressure (e.g., Mei et al., 2010; Jain et al., 2017). Furthermore, different authors apply stress cut-offs in the mantle, for example, to match tectonic plate size distribution in mantle convection simulations (e.g., Mallard et al., 2016) or apply reduced friction angles $\left(\leq 15^{\circ}\right)$, which further reduce with progressive plastic strain (down to $2^{\circ}$ ), in order to indirectly consider the weakening effects of fluids or other strain softening mechanisms (e.g., Erdős et al., 2014). Moreover, since the effective friction angle depends on fluid pressure, the appropriate friction angle for the mantle lithosphere is debated and, hence, different friction angles are often used for the mantle lithosphere in numerical models of subduction (e.g., Li et al., 2010). To test the impact of absolute stress magnitudes, we performed two more simulations with a reduced friction angle for the lithosphere (Fig. 13). The friction angle is reduced to limit maximal stress values but not to mimic any particular natural process. The standard value for the friction angle is $30^{\circ}$ and we decrease this angle to $5^{\circ}$ (Figs. $13 \mathrm{c}$ and f) and $1^{\circ}$ (Figs. $13 \mathrm{~d}$ and g) in the two additional simulations. The reduction of friction angle changes the topographic profiles around the flexural bulge of the subducting plate (Fig. 13a). A friction angle to $5^{\circ}$ generates a shorter flexural wavelength whereas a friction angle of $1^{\circ}$ does not generate a realistic flexural topography at all. These results are in broad agreement with results of Crameri et al. (2017) who, amongst others, also show a larger bulge and flexural wavelength with larger friction angle (their figure S10).

The reduction of friction angles reduces, as expected, the maximal absolute values of $\tau_{x x}$ (Figs. 13b-d) and changes the distribution of dominant deformation mechanism (Figs. 13e-g). In the simulation with a friction angle of $1^{\circ}$ a continued subduction cannot be established because the slab is thinned in the trench region and detaches, or breaks-off (Fig. 13g). The reduction of stress magnitudes makes the slab mechanically so weak that the slab pull force cannot be transmitted anymore to the horizontal 
regions of the lithosphere, the slab pull cannot drive horizontal plate motion anymore so that the slab detaches. For a friction angle of $5^{\circ}$ maximal absolute deviatoric stress magnitudes are between 50 and $100 \mathrm{MPa}$. Also, for a friction angle of $5^{\circ}$ the region with dominant frictional-plastic deformation is significantly larger than for a friction angle of $30^{\circ}$ (Fig. $13 \mathrm{e}$ and f). Particularly, the region of slab unbending (between 50 and $100 \mathrm{~km}$ depth and $200 \mathrm{~km}<\mathrm{x}<250 \mathrm{~km}$ in Fig. 13f) shows significant firctional-plastic deformation, which is not the case for a friction angle of $30^{\circ}$ (between 50 and $100 \mathrm{~km}$ depth and $200 \mathrm{~km}<x<250 \mathrm{~km}$ in Fig. 13e). Maximal absolute deviatoric stress magnitudes of a few hundred MPa seem to be required in order to generate a flexural wavelength corresponding to the Mariana trench, as is the case in the model with standard elastic shear modulus.

\section{Impact of boundary conditions}

We have also performed a forced subduction simulation (S7, Table 2 ) and a free subduction simulation (S8) using different boundary conditions than in reference models (SO, S1). In S7 we apply a horizontal velocity only at the right model side, but with a value of $10 \mathrm{~cm} \cdot \mathrm{yr}^{-1}$ so that the absolute convergence velocity is identical to the one of SO. After ca. 2.8 Ma the stress field and the slab geometry are similar for S0 and S7 (Fig. 14a and c). However, after ca. $4 \mathrm{Ma}$ the slab geometry and, hence, the associated stress field are different (Fig. 14b and d). In S8 we apply a weak zone at both lateral model sides so that the slab and overriding plate can detach from both lateral model sides. After ca. 6.9 Ma and ca. 8 Ma both simulations S1 and S8 exhibit a similar slab geometry and stress field. These additional simulations indicate that the applied boundary conditions have a significant impact on the forced subduction simulations but not on the free subduction simulations.

\section{5. - Discussion}

The deformation behaviour, the thermal structure and the mineral composition of the lithosphere are only approximately known and, hence, published numerical subduction models commonly differ in 
terms of the applied flow laws, temperature and density fields. Our models were not designed to closely match a specific subduction system and we used standard rheological models, and simple density and temperature fields. However, we assume that our mathematical model, the model configuration, the applied boundary conditions, the temperature field, the densities and the applied rheological model, including the different creep flow laws, generate a subduction process, which should be comparable, to the first order, to a natural ocean-ocean subduction system. To test whether the modelled effective deformation behaviour, such as flexure of the slab, and the modelled slab pull, controlled by the model density field, are indeed in broad agreement with natural observations, we compare our model results with a major subduction system, namely with real data from the Mariana subduction zone. We chose the Mariana trench because it is a prominent subduction zone and has been frequently used for the comparison with mathematical subduction models (e.g., Funiciello et al., 2003; Turcotte \& Schubert, 2014). We first compare topography of the ocean floor to assess the flexural behaviour of the lithosphere. Secondly, we compare modelled gravity anomalies with anomalies derived from data measured in the field in order to assess the density field (Figs. 15 and 16). For the topography comparison, we use the seafloor topography data from the Mariana trench (Funiciello et al., 2003; Turcotte \& Schubert, 2014). For the visual comparison between natural and calculated topography profiles, we have used the position of the trench $(x=0)$ as a reference (Fig. 15). The first-order topography of both forced and free subduction models fits the natural topography and the analytical solution of Turcotte \& Schubert (2014). Therefore, the applied flow laws and rheological behaviour of our model lithosphere, controlling the height of the flexural bulge and the flexural wavelength, broadly agree with the flexural behaviour of a natural oceanic lithosphere.

For the gravimetric comparison, we use the global WGM2012 model for free-air gravity anomaly, which has a resolution of 2'x2' (Bonvalot et al., 2012), and compare it with the synthetic free-air gravity anomalies calculated for our model density field (Fig. 16). We extract ten gravity anomaly profiles perpendicular to the trench from the WGM2012 (Fig. 16a). From the numerical models, we calculate 
two free-air anomaly profiles, one for the forced and one for the free subduction model (Fig. 16b). For comparison, we have co-located all gravity anomaly profiles at the trench (Fig. 16b). Our modelled free-air gravity anomalies agree with the long-wavelength variation of the observed anomaly. Modelled anomalies exhibit a similar width and amplitude in their spatial variation compared with the natural free-air gravity anomalies. The shorter wavelength variations and peaks in the natural gravity anomalies are due to the natural seafloor topography, reflecting the formation and deformation of the volcanic arc to the West of the Mariana trench and the seamounts to the East on the Pacific plate (Fig. 16a). These peaks vary across the selected 10 observed profiles and our model has not aimed at reproducing such short wavelength variations.

572 The comparison of model and natural topography allows evaluating the applicability of the modelled

573 flexural behaviour of the lithosphere to nature. This modelled flexural behaviour and the associated 574 topography is controlled by the considered deformation mechanisms, the flow laws and material 575 parameters (e.g. Zhong \& Gurnis, 1994; Crameri et al., 2017). Consequently, the topography comparison allows evaluating whether the employed flow laws and material parameters are applicable to natural cases. However, since natural topography can vary significantly between different subduction zones, different subduction zones likely exhibit different rheological and density characteristics (e.g., Crameri et al., 2019). The free surface implementation is therefore, well suited for the comparison of model and natural topography. A modelled free surface topography is also essential for the calculation of along-profile variations of $\triangle G P E$ (Figs. 5 and 6). The topography controls gravity anomalies, which further depend on the density field. We calculate the density with an equation of state (EOS), which depends on $T$ and $P$ (see Equation 4). We do not consider mineral phase transformation, which could affect the localization of deformation in this compressive setting (e.g., Hetényi et al., 2011). The comparison of gravity anomaly profiles from our model with natural free-air gravity anomaly profiles obtained across the Mariana trench shows that both of our model density

587 fields are appropriate; at least for the considered natural subduction zone (Fig. 16). Our simulations 
show differences in the forced and free subduction models. However, with respect to topography (e.g., bulge) or gravity anomalies, these differences are not significant (Figs. 15 and 16). The maximal amplitude of the modelled gravity anomaly profile for the free subduction model is larger than the one for the forced subduction model. However, considering the lateral variability of natural gravity anomaly profiles across the Mariana trench, both models fit the natural data to a good level. Alternative to gravity anomalies, $\triangle G P E$ profiles show larger differences between forced and free subduction models, because for a more vertical slab the $\triangle G P E$ anomaly is narrower (Figs. 5 and 6).

The calculated stress field (Fig. 11) shows that the subducting plate's outer bend of the hinge zone is under extension and the inner bend is under compression. This deformation distribution is expected for the subducting plate, but our model allows quantifying the contribution of individual deformation mechanism. The flexural behaviour varies along the subducting plate and in the downgoing plate the outer region of the plate is under compression and the inner one under extension (Fig. 11). This variation of flexural behaviour along the subducting slab is in agreement with analytical results of Ribe (2010) who shows that the sign of the rate of curvature changes along the slab. Ribe (2010) considered a simpler, linear viscous behaviour of the slab. The comparison with our results, considering five deformation mechanisms and temperature dependent flow laws, indicates that a linear viscous model can capture the first order flexural behaviour of a subducting slab. Regions with high compressive deviatoric stresses of several hundreds of $\mathrm{MPa}$ in the downgoing slab next to the subduction interface (Figs 11c and f) can be important for the interpretation of exhumed (ultra-)high pressure rocks. Subducted crustal rock units in the outer regions of subducting slabs could experience high stress and, hence, tectonic overpressure (e.g., Schmalholz \& Podladchikov, 2013; Moulas et al., 2019) before they are detached from the subducting plate and return to the surface. If the stress and, hence, the internal resistance of the slab is reduced, then a continuous subduction is not possible anymore because the slab detaches, and the slab pull force cannot be transferred anymore to the horizontal region of the 
613 lithospheric plate (Figs. 13d and g). This behaviour is consistent with the "shallow breakoff" of Duretz

614 et al. (2011a), which systematically occurred for weak slabs (young plates). This result agrees also with

615

616

617

618

619

620

621

622

623

624

625

626

627

628

629

630

631

632

633

634

635

636

637 predictions of the analytical model of Ribe (2010) who shows that the subduction velocity approaches the Stokes velocity of a detached object when the internal resistance of the slab becomes smaller than the external resistance of the material surrounding the slab.

Stress magnitude and distribution in subducting plates are one of the controlling parameters of intraslab processes such as earthquakes, metamorphism or fluid transfer. Our results show that in a subducting lithosphere all five considered deformation mechanisms are active and contribute to shape the total stress field (Fig. 8). Particularly, our results show that elastic deformation is the dominant deformation behaviour in large regions of the subducted slab (Fig. 8g). Therefore, models aiming to calculate the intra-plate stress field and intra-plate processes should consider the impact of elastic deformation on the stress field.

Our model results can contribute to a better understanding of the development of faults during plate flexure, and its importance for the hydration of the subducting plate. Several mechanisms have been proposed to bring water from the surface into the mantle, such as bending-related faulting (e.g., Ranero et al., 2003; Faccenda et al., 2008; Faccenda et al., 2009), thermal cracking (Korenaga, 2017) or seismic pumping (Sibson et al., 1975). The length and distribution of faults, which could develop by plate flexure, is therefore important to assess the water budget of the subducting plate. Furthermore, Peacock (2001) suggested that dehydration of antigorite (serpentine) by dehydration reactions could be an explanation for intermediate-depth earthquakes. To constrain the depth of faulting, and therefore the maximum depth where water could be added to the subducting plate is fundamental to test whether part of the earthquakes observed between 15 to $25 \mathrm{~km}$ depth could be explained by metamorphic dehydration reaction or not (Peacock, 2001). Our model predicts the formation of faults 
in the outer hinge zone of the subducting plate (Figs. $8 \mathrm{~g}$ and 9). These faults develop in a zone of ca. $100 \mathrm{~km}$ width around the bulge. These frictional-plastic faults reach a depth of ca. $40 \mathrm{~km}$. However, the spatial extent of faulting is highly dependent on the elasticity and plasticity parameters in the model. Figure 12 shows that the extent of plastic deformation changes drastically if the elastic deformation behaviour is modified.

Flexure of the subducting plate has been also proposed as an important mechanism for the formation of petit-spot volcanoes (Hirano et al., 2006). Petit-spot volcanoes represent small volumes of alkaline magmas that have been emitted on the top of the downgoing Pacific plate in front of Japan (Hirano et al., 2006). These magmas are emitted 300 to $600 \mathrm{~km}$ away from the trench, which could correspond to the region where the plate starts to bend (Hirano et al., 2006). Petit-spot volcanoes are, therefore, interpreted as the products of deformation-driven melt segregation of melt initially present at the base of the lithosphere. Since their first observation in front of Japan, petit-spot volcanoes have been identified in several subduction zone, such as Tonga (Hirano et al., 2008), Chile (Hirano et al., 2013), and Sunda trenches (Taneja et al., 2015), or as an accreted petit-spot in Costa Rica (Buchs et al., 2013). These observations suggest that petit-spot volcanism is a global process around subduction zones. In this context, the deformation behaviour and its changes along the lithosphere-asthenosphere boundary are critical to understand how low degrees of volatile rich melts can be extracted from the base of the lithosphere. Earlier models suggest that large flexural curvatures imposed on the pre-flexed lithosphere might instigate brittle fracturing even at the base of the lithosphere (Hirano et al., 2006; Yamamoto et al., 2014). Our Figure 8g shows, however, that deformation around the base of the lithosphere (from $50 \mathrm{~km}$ depth to the LAB) is likely controlled by diffusion and dislocation creep. Propagation of brittle faults down to the base of the lithosphere is, therefore, unlikely. Consequently, percolation of melts within the basal viscous region of the lithosphere, before its extraction by faults when the melts reach the elastic domain, seems a more realistic model for petit-spot formation. A 
possible mechanism of melt transport in the viscous region could be ascent in the form of porosity waves (e.g., Connolly \& Podladchikov, 2007). The viscous percolation model is in agreement with recent multiple saturation laboratory experiments which show that petit-spot melts equilibrate last with the mantle phases (olivine, orthopyroxene, and clinopyroxene) at pressures between 1.8 and 2.1 GPa and at temperatures around $1^{\prime} 280-1^{\prime} 290^{\circ} \mathrm{C}$, which are P-T conditions corresponding to the lithosphere rather than the top of the asthenosphere (Machida et al., 2017). Another argument in favour for the ascent and equilibration of low degree melts at the base of the lithosphere is the presence in petit-spot lavas with xenoliths showing evidence of metasomatic enrichment (Pilet et al., 2016). One important question concerning petit-spot formation is which process or parameter initiates melt percolation in the basal part of the lithosphere. The porosity at the base of the lithosphere is frequently considered as too small to allow for silicate melt percolation. Our numerical model allows quantifying the extension produced by plate flexure. Figure 11 suggests that the base of the lithosphere where the plate starts to bend is slightly in extension, but the effect is very limited at depths greater than $50 \mathrm{~km}$ where absolute magnitudes of $\tau_{x x}$ are significantly less than $10 \mathrm{MPa}$. Nevertheless, the current model considers a homogeneous dry-olivine lithology and future models considering additionally wet or higher-porosity domains at the base of the lithosphere, i.e., in the low seismic velocity zone, will be important to constrain the effect of plate flexure on the stress state at the base of the lithosphere.

\section{6. - Conclusions}

We performed 2D thermo-mechanical numerical simulations of subduction, considering both forced and free subduction regimes as well as a composite rheological model including elasticity, frictionalplasticity, diffusion, dislocation and Peierls creep. In the forced subduction regime, we initiate subduction by applying horizontal boundary velocities. The initiation by a forced subduction must generate an embryonic slab to continue a free subduction simulation, for which boundary velocities 
are set to zero and subduction is driven by buoyancy forces of the slab. For our configuration, the embryonic slab should produce a slab pull force (per unit length) of at least $1.8 \mathrm{TN} \cdot \mathrm{m}^{-1}$ so that free subduction can occur.

We show that the five employed deformation mechanisms are all important for the evolution of the subducting lithospheric plate for both forced and free subduction. Particularly, elastic deformation is important because it affects the flexural behaviour, the magnitude and distribution of deviatoric stresses and the distribution of dominant deformation mechanisms. Simulations with an unrealistic, reduced impact of elasticity show significantly larger stress magnitudes and larger regions with high stresses in the subducting and overriding plate than corresponding simulations with appropriate elasticity. For our model configuration, the simulations with elasticity also fit best the natural flexural bulge and wavelength of the Mariana subduction zone. Therefore, including elasticity in numerical subduction models seems important for an appropriate calculation of stresses, of the distribution of deformation mechanisms and of flexure in a subduction system.

We also show that a subduction system generates along-profile variations of GPE corresponding to horizontal driving forces in the lithosphere-asthenosphere system. These GPE variations result from either topography variations associated to plate flexure or from deeper density variations caused by subduction of the lithosphere into the asthenosphere. For both forced and free subduction models the GPE variations cause compressive forces in the trench region and extensive forces in front and behind the trench region. These latter likely have strong impact on driving petrological processes such as melt migration across the lithosphere, at significant distance from the trench.

Although our models were not specifically designed for reproducing a particular subduction zone, the simulation results closely match natural seafloor topography and free-air gravity anomalies across the Mariana trench. This fit indicates that our model density field and the applied rheological model generate buoyancy and flexural stresses in agreement with this particular natural subduction zone. Calculated maximal absolute values of deviatoric stresses in the bending and subducting lithosphere 
are approximately $500 \mathrm{MPa}$. If absolute magnitudes of maximal deviatoric stresses are significantly less than $100 \mathrm{MPa}$, caused for example by a reduced friction angle, continuation of subduction does not occur because the denser subducting slab detaches from the lithosphere. Hence, deviatoric stress magnitudes of several hundreds of MPa are required for a continuous subduction. The uppermost region of the oblique, subducting slab shows high compressive stress, due to unbending, directly next to the subduction interface. Such high compressive stress may affect metamorphic reactions in rock units before they are detached from the subducting slab and exhumed to the surface.

\section{Acknowledgements}

We thank Fabio Crameri and an anonymous reviewer for very helpful and constructive reviews. This work was supported by the University of Lausanne.

\section{References}

Babeyko, A.Y., Sobolev, S.V, 2008. High-resolution numerical modeling of stress distribution in viscoelasto-plastic subducting slabs, Lithos, 103(1-2), 205-216. doi.org/10.1016/j.lithos.2007.09.015 Bonvalot, S., Balmino, G., Briais, A., Kuhn, M., Peyrefitte, A., Vales, N., Biancale, R., Gabalda, G., Reinquin, F., Sarrailh, M., 2012. World Gravity Map. Commission for the Geological Map of the World. Eds. BGI-CGMW-CNES-IRD, Paris.

Buchs, D.M., Pilet, S., Cosca, M., Flores, K.E., Bandini, A.N., Baumgartner, P.O., 2013. Low-volume intraplate volcanism in the Early/Middle Jurassic Pacific basin documented by accreted sequences in Costa Rica, Geochem. Geophys. Geosyst., 14, 1552-1568. doi.org/10.1002/ggge.20084 
Burov, E.B., 2010. The equivalent elastic thickness (Te), seismicity and the long-term rheology of continental lithosphere: time to burn-out "crème brûlée"?: insights from large-scale geodynamic modelling, Tectonophysics, 484(1-4), 4-26. doi.org/10.1016/j.tecto.2009.06.013

Burov, E.B., 2011. Rheology and strength oft he lithosphere, Marine and Petroleum Geology, 28, 14021443. doi.org/10.1016/j.marpetgeo.2011.05.008

Chertova, M.V., Geenen, T., van den Berg, A., Spakman, W., 2012. Using open sidewalls for modelling self-consistent lithosphere subduction dynamics, Solid Earth, 3, 313-326. doi.org/10.5194/se-3-3132012

Čižková , H., van Hunen, J., van den Berg, A., 2007. Stress distribution within subducting slabs and their deformation in the transition zone, Phys. Earth planet. Inter., 161(3-4), 202-214. doi.org/10.1016/j.pepi.2007.02.002

Connolly, J.A.D., Podladchikov, Y.Y, 2007. Decompaction weakening and channeling instability in ductile porous media: Implications for asthenospheric melt segregation, J. geophys. Res: Solid Earth, 112, B10205. doi.org/10.1029/2005JB004213

Crameri, F., Tackley, P.J., Meilick, I., Gerya, T.V., Kaus, B.J.P., 2012. A free plate surface and weak oceanic crust produce single-sided subduction on Earth, Geophysical Research Letters, 39(3), L03306. doi.org/10.1029/2011GL050046

Crameri, F., Lithgow-Bertelloni, C.R., Tackley, P.J., 2017. The dynamical control of subduction parameters on surface topography, Geochem. Geophys. Geosyst., 18, 1661-1687. doi.org/10.1002/2017GC006821

Crameri, F., 2018. Scientific colour-maps. Zenodo. http://doi.org/10.5281/zenodo.1243862

Crameri, F., Conrad, C.P., Montési, L., Lithgow-Bertelloni, C.R., 2019. The dynamic life of an oceanic plate, Tectonophysics, 760, 107-135. doi.org/10.1016/j.tecto.2018.03.016 
Duretz, T., Gerya, T.V., May, D.A., 2011. Numerical modelling of spontaneous slab breakoff and $\begin{array}{lllll}\text { subsequent } & \text { topographic } & \text { 244-256. }\end{array}$ doi.org/10.1016/j.tecto.2010.05.024

Duretz, T., May, D.A., Gerya, T.V., Tackley, P.J., 2011. Discretization errors and free surface stabilization in the finite difference and marker-in-cell method for applied geodynamics: A numerical study, Geochem. Geophys. Geosyst., 12, Q07004. doi.org/10.1029/2011GC003567

Duretz, T., Gerya, T.V., Spakman, W., 2014. Slab detachment in laterally varying subduction zones: 3-D numerical modelling, Geophys. Res. Lett., 41, 1951-1956. doi.org/10.1002/2014GL059472

Duretz, T., May, D.A., Yamato, P., 2016. A free surface capturing discretization for the staggered grid finite difference scheme, Geophys. J. Int., 204, 1518-1530. doi.org/10.1093/gji/ggv526

Erdős, Z., Huismans, R.S., van der Beek, P., Thieulot, C., 2014. Extensional inheritance and surface processes as controlling factors of mountain belt structure, J. geophys. Res.: Solid Earth, 119(12), 90429061. doi.org/10.1002/2014JB011408

Faccenda, M., Burlini, L., Gerya, T.V., Mainprice, D., 2008. Fault-induced seismic anisotropy by hydration in subducting oceanic plates, Nature, 455, 1097-1100. doi.org/10.1038/nature07376

Faccenda, M., Gerya, T.V., Burlini, L., 2009. Deep slab hydration induced by bending-related variations in tectonic pressure, Nat. Geosci., 2, 790-793. doi.org/10.1038/ngeo656

Faccenda, M., Gerya, T. V., Mancktelow, N. S., Moresi, L., 2012. Fluid flow during slab unbending and dehydration: Implications for intermediate-depth seismicity, slab weakening and deep water recycling, Geochem. Geophys. Geosyst., 13(1), Q01010. doi.org/10.1029/2011GC003860

Farrington, R.J., Moresi, L.-N., Capitanio, F.A., 2014. The role of viscoelasticity in subducting plates, Geochem. Geophys. Geosyst., 15, 4291-4304. doi.org/10.1002/2014GC005507

Funiciello, F., Morra, G., Regenauer-Lieb, K., Giardini, D., 2003. Dynamics of retreating slabs: 1. Insights from two-dimensional numerical experiments, J. geophys. Res.: Solid Earth, 108(B4), 2206. doi.org/10.1029/2001JB000898 
Garel, F., Goes, S., Davies, D., Davies, J.H., Kramer, S.C., Wilson, C.R., 2014. Interaction of subducted slabs with the mantle transition-zone: A regime diagram from 2-d thermomechanical models with a mobile trench and an overriding plate, Geochem. Geophys. Geosyst., 15, 1739-1765. doi.org/10.1002/2014GC005257

Gerya, T., 2011. Future directions in subduction modeling. J. Geodyn., 52, 344-378. doi.org/10.1016/j.jog.2011.06.005

Gerya, T., 2019. Introduction to Numerical Geodynamic Modelling, 2nd ed. Cambridge University Press, Cambridge. doi.org/10.1017/9781316534243

Goetze, C., Evans, B., 1979. Stress and temperature in the bending lithosphere as constrained by experimental rock mechanics, Geophys. J. Int., 59, 463-478. doi.org/10.1111/j.1365246X.1979.tb02567.x

Gripp, A.E., Gordon, R.G., 1990. Current plate velocities relative to the hotspots incorporating the NUVEL-1 global plate motion model, Geophys. Res. Lett., 17, 1109-1112. doi.org/10.1029/GL017i008p01109

Gurnis, M., Hall, C., Lavier, L., 2004. Evolving force balance during incipient subduction, Geochem. Geophys. Geosyst., 5, Q07001. doi.org/10.1029/2003GC000681

Hassani, R., Jongmans, D., Chéry, J., 1997. Study of plate deformation and stress in subduction processes using two-dimensional numerical models, J. geophys. Res.: Solid Earth, 102(B8), 1795117965. doi.org/10.1029/97JB01354

Hetényi, G., Godard, V., Cattin, R., Connolly, J.A.D., 2011. Incorporating metamorphism in geodynamic models: the mass conservation problem, Geophys. J. Int., 186(1), 6-10. doi.org/10.1111/j.1365246X.2011.05052.x

Holt, A.F., Becker, T.W., Buffett, B.A., 2015. Trench migration and overriding plate stress in dynamic subduction models, Geophys. J. Int., 201(1), 172-192. doi.org/10.1093/gji/ggv011 
Hirano, N., Takahashi, E., Yamamoto, J., Abe, N., Ingle, S.P., Kaneoka, I., Hirata, T., Kimura, J.-I., Ishii, T., Ogawa, Y., Machida, S., Suyehiro, K., 2006. Volcanism in Response to Plate Flexure, Science New Series, 313, 1426-1428. doi.org/10.1126/science.1128235

Hirano, N., Koppers, A.A.P., Takahashi, A., Fujiwara, T., Nakanishi, M., 2008. Seamounts, knolls and petit-spot monogenetic volcanoes on the subducting Pacific Plate, Basin Res., 20, 543-553. doi.org/10.1111/j.1365-2117.2008.00363.x

Hirano, N., Machida, S., Abe, N., Morishita, T., Tamura, A., Arai, S., 2013. Petit-spot lava fields off the central Chile trench induced by plate flexure, Geochem. J., 47, $249-257$. doi.org/10.2343/geochemj.2.0227

Hirth, G., Kohlstedt, D., 2003. Rheology of the Upper Mantle and the Mantle Wedge: A View from the Experimentalists. In Inside the Subduction Factory, J. Eiler (Ed.). doi.org/10.1029/138GM06 Jain, C., Korenaga, J., Karato, S.I., 2017. On the yield strength of oceanic lithosphere. Geophysical Research Letters, 44(19), 9716-9722. doi.org/10.1002/2017GL075043

Jaquet, Y., Duretz, T., Schmalholz, S.M., 2016. Dramatic effect of elasticity on thermal softening and strain localization during lithospheric shortening, Geophys. J. Int., 204, 780-784. doi.org/10.1093/gji/ggv464

Kameyama, M., Yuen, D.A., Karato, S.-I., 1999. Thermal-mechanical effects of low-temperature plasticity (the Peierls mechanism) on the deformation of a viscoelastic shear zone, Earth planet. Sci. Lett., 168, 159-172. doi.org/10.1016/S0012-821X(99)00040-0

Kawakatsu, H., Kumar, P., Takei, Y., Shinohara, M., Kanazawa, T., Araki, E., Suyehiro, K., 2009. Seismic Evidence for Sharp Lithosphere-Asthenosphere Boundaries of Oceanic Plates, Science, 324, 499-502. doi.org/10.1126/science.1169499

Kearey, P., Klepeis, K.A., Vine, F.J., 2009. Global tectonics, 3rd ed. ed. Wiley-Blackwell, Oxford ; Chichester, West Sussex; Hoboken, NJ. 
Korenaga, J., 2017. On the extent of mantle hydration caused by plate bending, Earth planet. Sci. Lett., 457, 1-9. doi.org/10.1016/j.epsl.2016.10.011

Li, Z.H., Gerya, T.V., Burg, J.P., 2010. Influence of tectonic overpressure on P-T paths of HP-UHP rocks in continental collision zones: thermomechanical modelling, Journal of Metamorphic Geology, 28(3), 227-247. doi.org/10.1111/j.1525-1314.2009.00964.x

Liu, X., Zhao, D., 2016. P and S wave tomography of Japan subduction zone from joint inversions of local and teleseismic travel times and surface-wave data, Phys. Earth planet. Inter., 252, 1-22. doi.org/10.1016/j.pepi.2016.01.002

Machida, S., Kogiso, T., Hirano, N., 2017. Petit-spot as definitive evidence for partial melting in the asthenosphere caused by CO2, Nat. Commun., 8, 14302. doi.org/10.1038/ncomms14302

Mallard, C., Coltice, N., Seton, M., Müller, R.D., Tackley, P.J., 2016. Subduction controls the distribution and fragmentation of Earth's tectonic plates, Nature, 535, 140-143. doi.org/10.1038/nature17992

Mei, S., Suzuki, A.M., Kohlstedt, D.L., Dixon, N.A., Durham, W.B., 2010. Experimental constraints on the strength of the lithospheric mantle, J. geophys. Res.: Solid Earth, 115, B08204. doi.org/10.1029/2009JB006873

Molnar, P., Lyon-Caen, H., 1988. Some simple physical aspects of the support, structure, and evolution of mountain belts, in: Clark, S.P., Jr., Burchfiel, B.C., Suppe, J. (Eds.), Processes in Continental Lithospheric Deformation. Geological Society of America. doi.org/10.1130/SPE218-p179

Molnar, P., England, P., Martinod, J., 1993. Mantle dynamics, uplift of the Tibetan Plateau, and the Indian Monsoon, Rev. Geophys., 31(4), 357-396. doi.org/10.1029/93RG02030

Moresi, L., Dufour, F., Mühlhaus, H.-B., 2003. A Lagrangian integration point finite element method for large deformation modeling of viscoelastic geomaterials, J. Computational Physics, 184(2), 476-497. doi.org/10.1016/S0021-9991(02)00031-1 
855

856

857

858

859

860

861

862

863

864

865

866

867

868

869

870

871

872

873

874

875

876 877 simulating large deformations of heterogeneous, viscoelastic materials, Geophys. J. Int., 145, 199-208.

878 doi.org/10.1046/j.0956-540x.2000.01371.x

Moulas, E., Schmalholz, S.M., Podladchikov, Y.Y., Tajčmanová, L., Kostopoulos, D., \& Baumgartner, L.P. 2019. Relation between mean stress, thermodynamic, and lithostatic pressure. Journal of metamorphic geology, 37(1), 1-14. doi.org/10.1111/jmg.12446

Peacock, S.M., 2001. Are the lower planes of double seismic zones caused by serpentine dehydration in subducting oceanic mantle?, Geology, 29, 299. doi.org/10.1130/00917613(2001)029<0299:ATLPOD>2.0.CO;2

Pilet, S., Abe, N., Rochat, L., Kaczmarek, M.-A., Hirano, N., Machida, S., Buchs, D.M., Baumgartner, P.O., Müntener, O., 2016. Pre-subduction metasomatic enrichment of the oceanic lithosphere induced by plate flexure, Nat. Geosci., 9, 898-903. doi.org/10.1038/ngeo2825

Plümper, O., John, T., Podladchikov, Y.Y., Vrijmoed, J.C., Scambelluri, M., 2016. Fluid escape from subduction zones controlled by channel-forming reactive porosity, Nat. Geosci., 10, 150-156. doi.org/10.1038/ngeo2865

Popov, A.A., Sobolev, S.V., 2008. SLIM3D: A tool for three-dimensional thermomechanical modeling of lithospheric deformation with elasto-visco-plastic rheology, Phys. Earth planet. Inter., 171, 55-75. doi.org/10.1016/j.pepi.2008.03.007

Ranero, C.R., Phipps Morgan, J., McIntosh, K., Reichert, C., 2003. Bending-related faulting and mantle serpentinization at the Middle America trench, Nature, 425, 367-373. doi.org/10.1038/nature01961 Ribe, N.M., 2010. Bending mechanics and mode selection in free subduction: a thin-sheet analysis, Geophys. J. Int., 180, 559-576. doi.org/10.1111/j.1365-246X.2009.04460.x

Schellart, W.P., Freeman, J., Stegman, D.R., Moresi, L., May, D., 2007. Evolution and diversity of subduction zones controlled by slab width, Nature, 446, 308. doi.org/10.1038/nature05615

Schmalholz, S.M., Podladchikov, Y.Y., Schmid, D.W., 2001. A spectral/finite difference method for 
879

880

881

882

883

884

885

886

887

888

889

890

891

892

893

894

895

896

897

898

899

900

901

902

903

Schmalholz, S.M., Fletcher, R.C., 2011. The exponential flow law applied to necking and folding of a ductile layer, Geophys. J. Int., 184, 83-89. doi.org/10.1111/j.1365-246X.2010.04846.x

Schmalholz, S.M., Podladchikov, Y.Y., 2013. Tectonic overpressure in weak crustal-scale shear zones and implications for the exhumation of high-pressure rocks. Geophysical Research Letters, $\mathbf{4 0 ( 1 0 ) ,}$ 1984-1988. doi.org/10.1002/grl.50417

Schmalholz, S.M., Medvedev, S., Lechmann, S.M., Podladchikov, Y., 2014. Relationship between tectonic overpressure, deviatoric stress, driving force, isostasy and gravitational potential energy, Geophys. J. Int., 197, 680-696. doi.org/10.1093/gji/ggu040

Schmalholz, S.M., Duretz, T., 2017. Impact of grain size evolution on necking in calcite layers deforming by combined diffusion and dislocation creep, J. Struct. Geol., 103, 37-56. doi.org/10.1016/j.jsg.2017.08.007

Schmalholz, S.M., Duretz, T., Hetényi, G., Medvedev, S., 2019. Distribution and magnitude of stress due to lateral variation of gravitational potential energy between Indian lowland and Tibetan plateau, Geophys. J. Int., 216, 1313-1333. doi.org/10.1093/gji/ggy463

Schmeling, H., Babeyko, A.Y., Enns, A., Faccenna, C., Funiciello, F., Gerya, T., Golabek, G.J., Grigull, S., Kaus, B.J.P., Morra, G., Schmalholz, S.M., van Hunen, J., 2008. A benchmark comparison of spontaneous subduction models-Towards a free surface, Phys. Earth planet. Inter., 171, 198-223. doi.org/10.1016/j.pepi.2008.06.028

Sibson, R.H., Moore, J.Mc.M., Rankin, A.H., 1975. Seismic pumping-a hydrothermal fluid transport mechanism, J. Geol. Soc., 131(6), 653-659. doi.org/10.1144/gsjgs.131.6.0653

Sobolev, S.V., Babeyko, A.Y., Koulakov, I., Oncken, O., 2006. Mechanism of the Andean orogeny: insight from numerical modelling, The Andes. Springer, Berlin, Heidelberg, 513-535.

Stern, R.J., 2002. Subduction zones. Reviews of geophysics, 40(4), 3-1. doi:10.1029/2001RG000108

Stern, R.J., Gerya, T., 2018. Subduction initiation in nature and models: A review, Tectonophysics, 746, 173-198. doi.org/10.1016/j.tecto.2017.10.014 
904

905

906

907

908

909

910

911

912

Talwani, M., Worzel, J.L., Landisman, M., 1959. Rapid gravity computations for two-dimensional bodies with application to the Mendocino submarine fracture zone, J. Geophys. Res., 64(1), 49-59. doi.org/10.1029/JZ064i001p00049

Taneja, R., O’Neill, C., Lackie, M., Rushmer, T., Schmidt, P., Jourdan, F., 2015. $40 \mathrm{Ar} / 39 \mathrm{Ar}$ geochronology and the paleoposition of Christmas Island (Australia), Northeast Indian Ocean, Gondwana Res., 28, 391-406. doi.org/10.1016/j.gr.2014.04.004

Toth, J., Gurnis, M., 1998. Dynamics of subduction initiation at preexisting fault zones, J. geophys. Res.: Solid Earth, 103, 18053-18067. doi.org/10.1029/98JB01076

Turcotte, D., Schubert, G., 2014. Geodynamics, 3rd ed. Cambridge, UK: Cambridge University Press. Won, I.J., Bevis, M., 1987. Computing the gravitational and magnetic anomalies due to a polygon: Algorithms and Fortran subroutines, Geophysics, 52, 232-238. doi.org/10.1190/1.1442298 Yamamoto, J., Korenaga, J., Hirano, N., Kagi, H., 2014. Melt-rich lithosphere-asthenosphere boundary inferred from petit-spot volcanoes, Geology, 42, 967-970. doi.org/10.1130/G35944.1

Yamato, P., Agard, P., Burov, E., Le Pourhiet, L., Jolivet, L., Tiberi, C., 2007. Burial and exhumation in a subduction wedge: Mutual constraints from thermomechanical modeling and natural P-T-t data (Schistes Lustrés, western Alps) , J. Geophys. Res., 112, B07410. doi.org/10.1029/2006JB004441

Yamato, P., Husson, L., Braun, J., Loiselet, C., Thieulot, C., 2009. Influence of surrounding plates on 3D subduction dynamics, Geophys. Res. Lett., 36, L07303. doi.org/10.1029/2008GL036942

Youngs, R.R., Chiou, S.J., Silva, W.J., \& Humphrey, J. R., 1997. Strong ground motion attenuation relationships for subduction zone earthquakes. Seismological Research Letters, 68(1), 58-73.

Zhong, S., Gurnis, M., 1994. Controls on trench topography from dynamic models of subducted slabs, J. geophys. Res.: Solid Earth, 99(B8), 15683-15695. doi.org/10.1029/94JB00809 

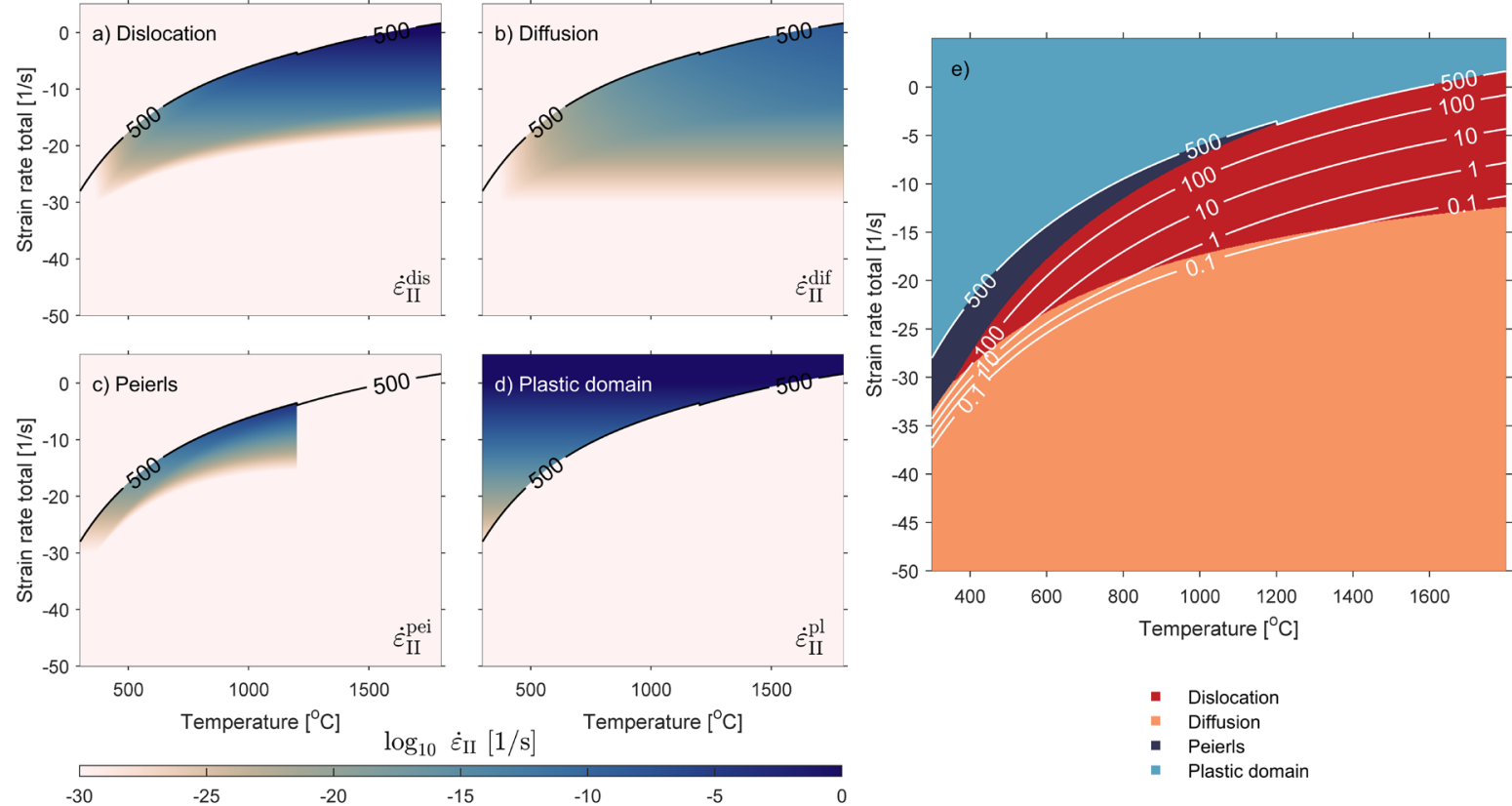

927

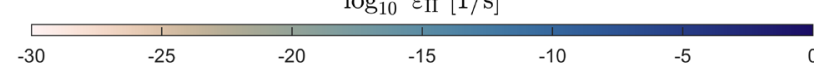

- Dislocation

- Diffusion

- Peierls

- Plastic domain

928 Figure 1. Individual strain rates of dissipative deformation mechanisms for (a) dislocation creep, (b) diffusion creep, (c) Peierls

929 creep and (d) plastic deformation as function of temperature and total strain rate for the applied rheology of the mantle. In

930 panels $(a-d)$, the highest individual strain rates for each deformation mechanism are shown in dark blue, while the slower are

931 in light beige. Calculations made at a pressure of $1 \mathrm{GPa}$ with a grain size of $5 \mathrm{~mm}$. The panel (e) shows the corresponding

dominant deformation mechanism map as identified by the legend. The black and white curves are lines of constant stresses 
a)
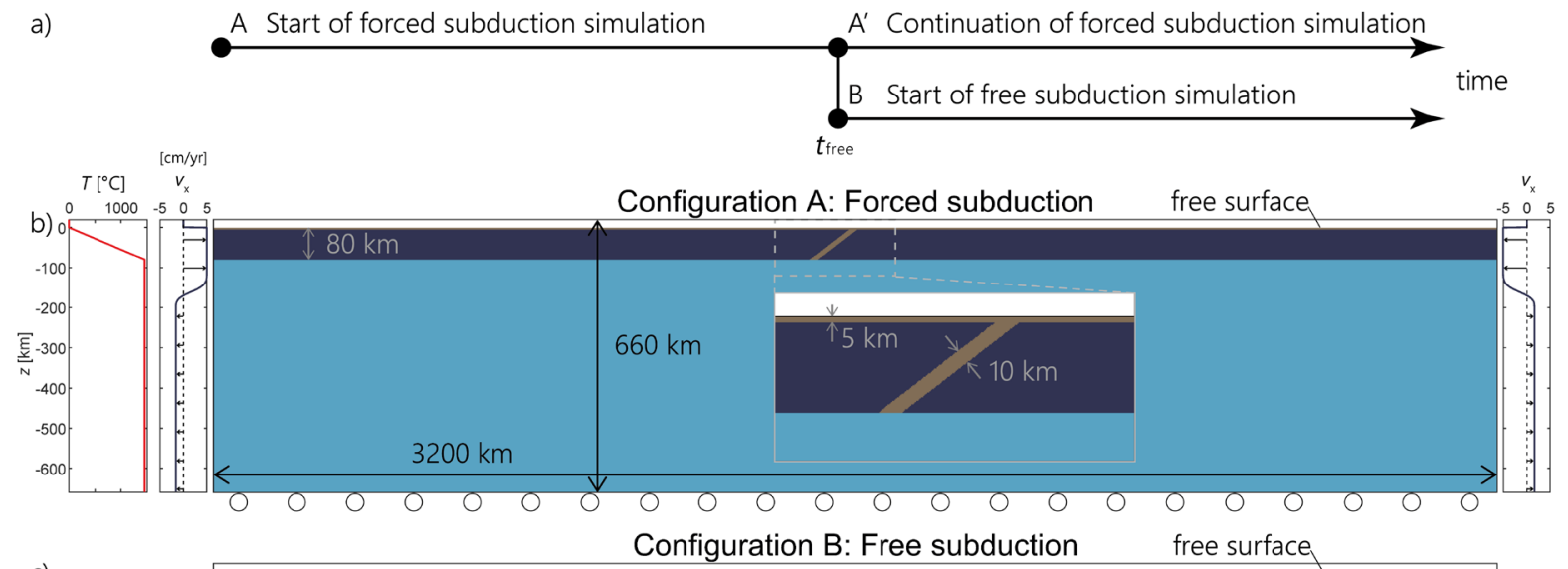

c)

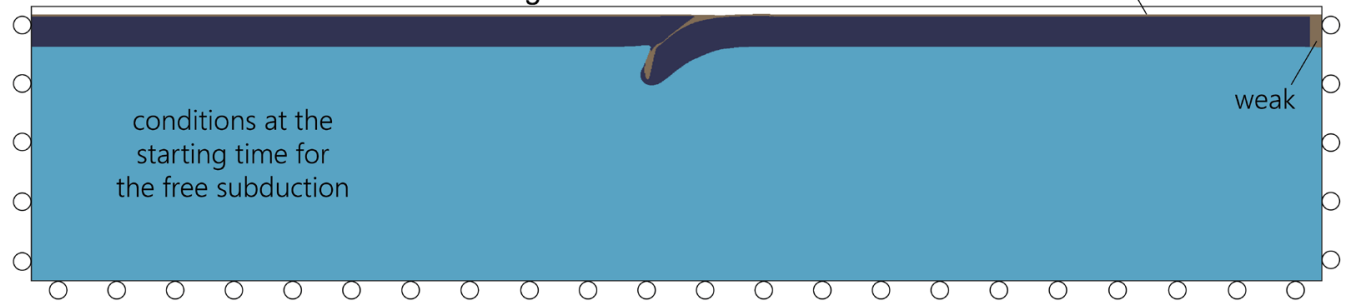

937 Figure 2. Panel (a) shows the time-line sketch of our simulations. Panels (b) and (c) show the model configurations (b) for the

938 forced subduction and (c) for the free subduction. Dark blue areas indicate the lithosphere. Brown areas indicate the initial weak zone. Light blue areas indicate the asthenosphere. Weak domain's width in panel (c) is $30 \mathrm{~km}$. 

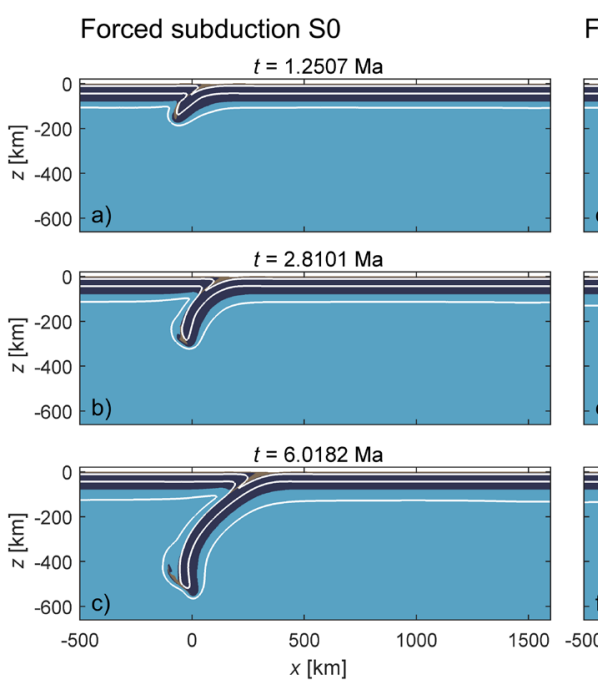

943 Figure 3. Visualisations of the forced subduction model in panels (a-c), the free subduction model where the subduction

944 continues (successful) with $t_{\text {free }}=1.25 \mathrm{Ma}$ in panels $(d-f)$, and the free subduction model where the subduction stops and

945 delaminates (failed) with $t_{\text {free }}=1.17 \mathrm{Ma}$ in panels ( $\mathrm{g}$-i). Material parameters are identical in all three simulations. The time

946 evolution is chosen for different slab length. Panels (a), (d) and $(g)$ show results for a slab of $75 \mathrm{~km}$, the length of the slab

947 required to initiate the free subduction. Panels (b), (e) and (h) show results for a slab of $310 \mathrm{~km}$ and subplots (c), (f) and (i)

948 show results for a slab of $550 \mathrm{~km}$. White lines show the isothermal contours for 200,800 and $1^{\prime} 440^{\circ} \mathrm{C}$. 

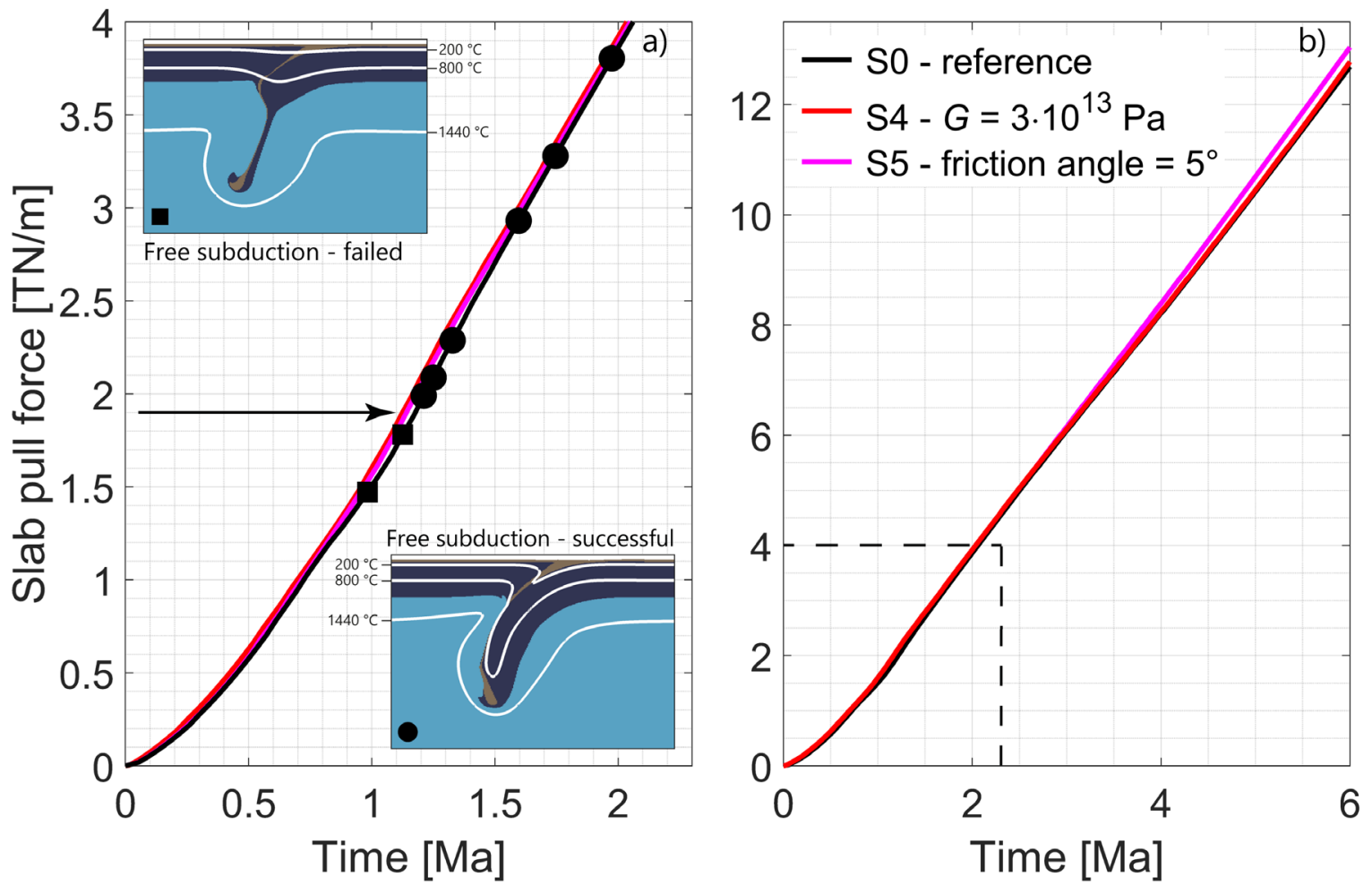

952 Figure 4. Diagrams showing the evolution of slab pull force with time, panel (a) is a zoom from panel (b). These diagrams evaluates the conditions required to develop a free subduction from the forced subduction simulation of reference SO (in black).

Free subduction simulations start after a period during which plates are pushed until initiation of free subduction. The different

points in panel (a) show the slab pull force for different starting times ( $t_{\text {free, }}$ see Fig. $2 a$ ). This $t_{\text {free }}$ is the duration of plate push

to initiate the subduction in the initial part of the free subduction model simulation. Squares show conditions where free 


\section{Forced subduction S0}
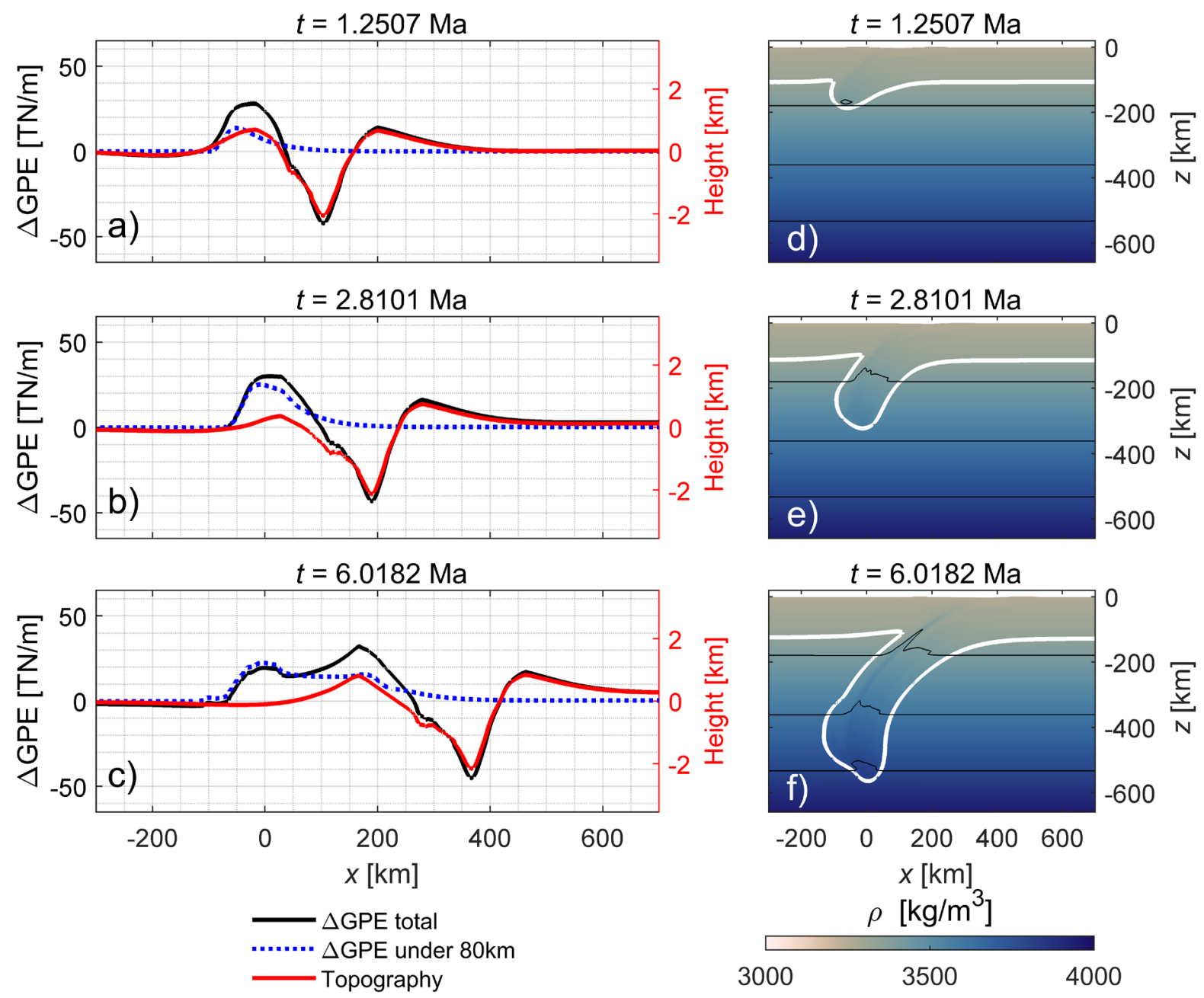

963 Figure 5. Panels $(a-c)$ show the evolution in time, same condition then Figs 3a-c, of the variations of total $\triangle G P E, \triangle G P E$ beneath

$96480 \mathrm{~km}$ and topography for the forced subduction model. Vertical left (black) axes are for the $\triangle G P E$ values and vertical right 


\section{Free subduction S1}
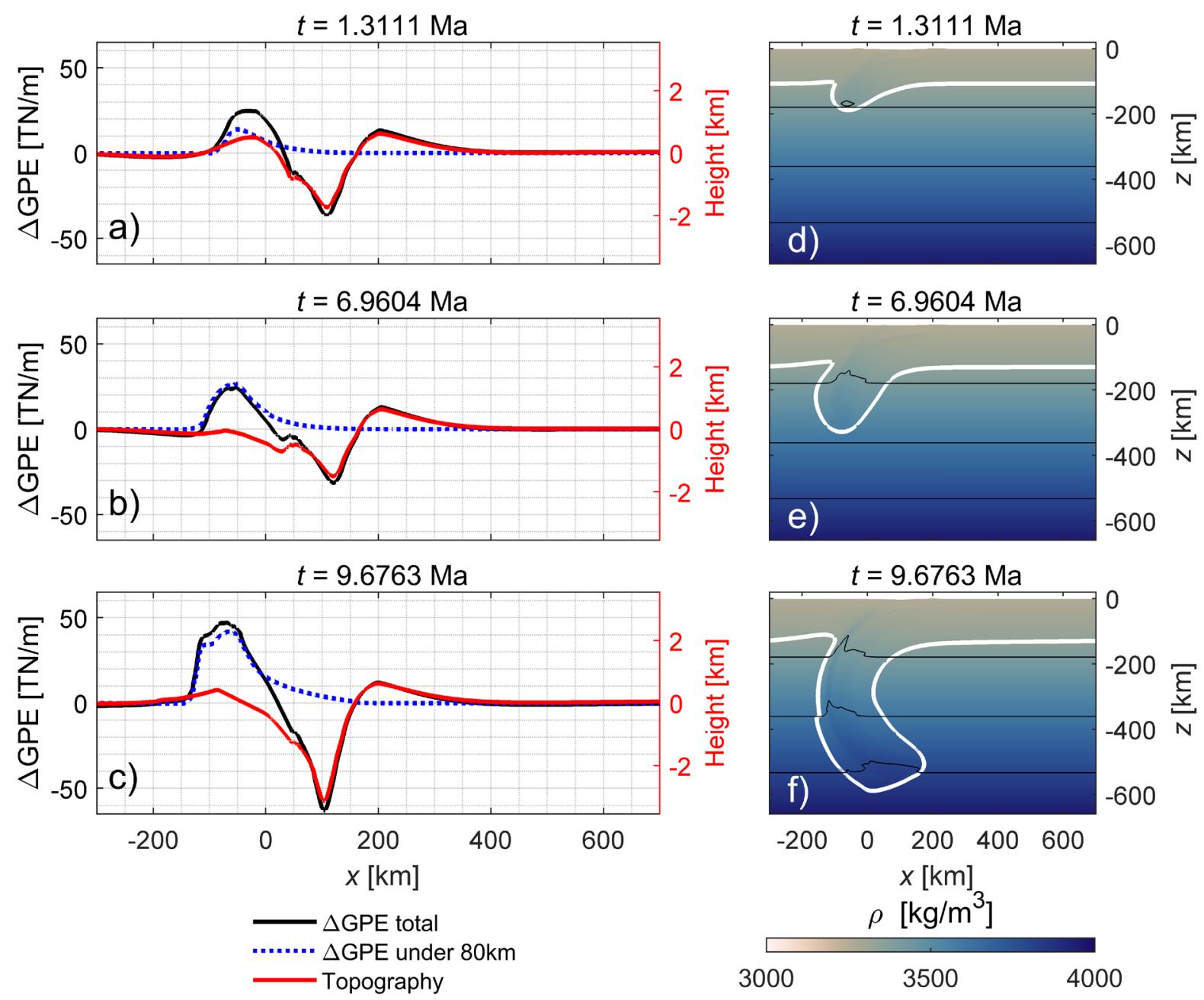

971 Figure 6. Panels $(a-c)$ show the evolution in time, same condition then Figs $3 d$-f, of the variations of total $\triangle G P E, \triangle G P E$ beneath

$97280 \mathrm{~km}$ and topography for the free subduction model. Vertical left (black) axes are for the $\triangle G P E$ values and vertical right (red)

973 axes are for topography values. Panels (d-f) show the evolution of density in the region of the subduction zone at corresponding

974 model times. White line is a temperature iso-contour for $1^{\prime} 440^{\circ} \mathrm{C}$ representing the $L A B$. Black lines are iso-contours of density

$975\left(3^{\prime} 400,3^{\prime} 600\right.$ and $\left.3^{\prime} 800 \mathrm{~kg} / \mathrm{m}^{3}\right)$. 


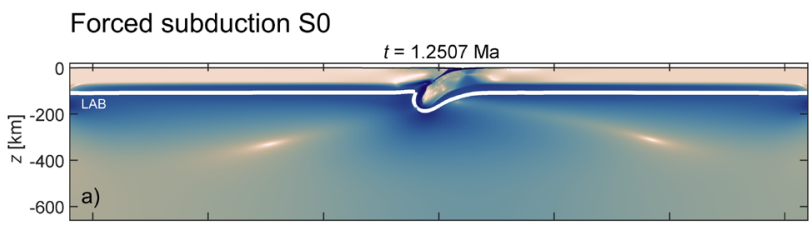

Free subduction S1
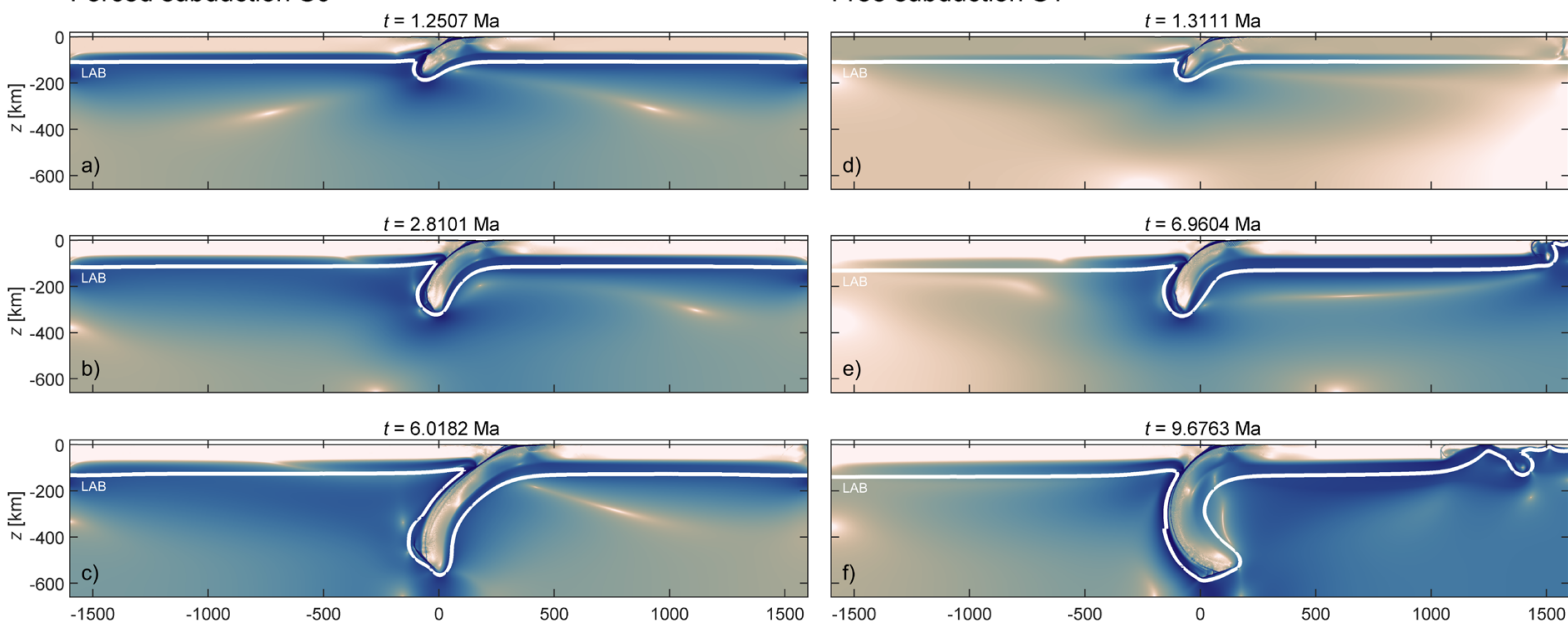

$=6.0182 \mathrm{Ma}$

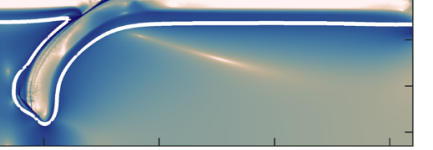

$\log _{10} \quad \dot{\varepsilon}_{\mathrm{II}}[1 / \mathrm{s}]$

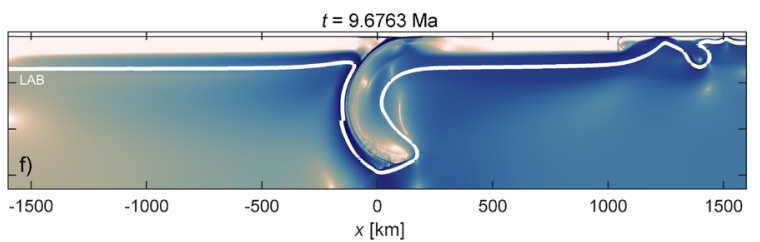

978

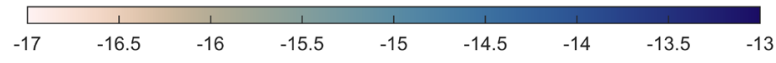

979 Figure 7. Second strain rate invariant evolution for the forced subduction model, (a-c), and for the free subduction model, (d- 

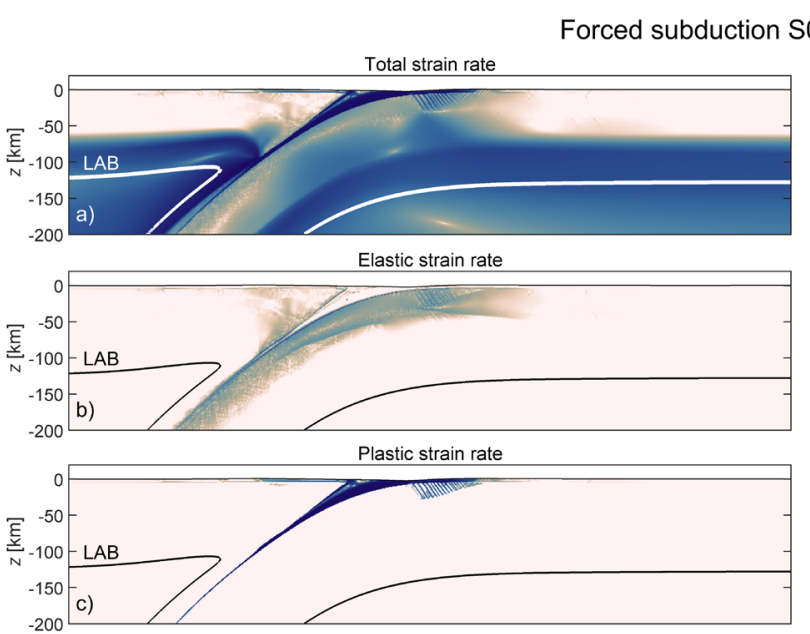

Distribution of deformation mechanisms

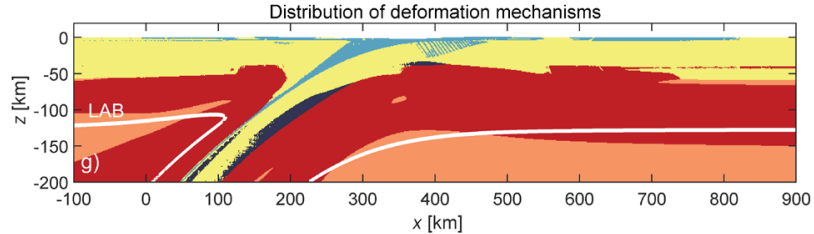

$\log _{10} \dot{\varepsilon}_{\mathrm{II}}[1 / \mathrm{s}]$
983

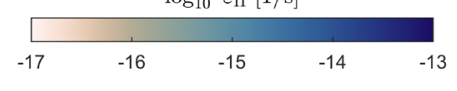

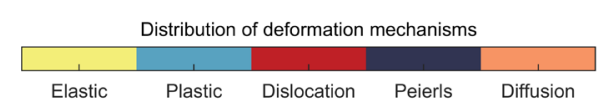

Diffusion strain rate

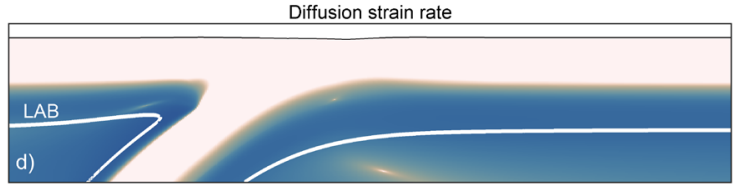

Dislocation strain rate

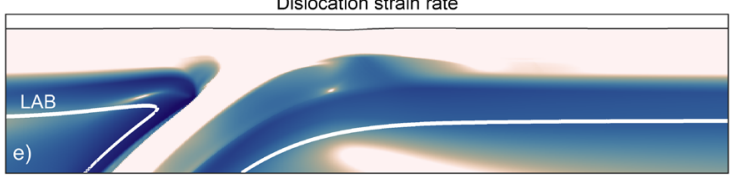

Peierls strain rate

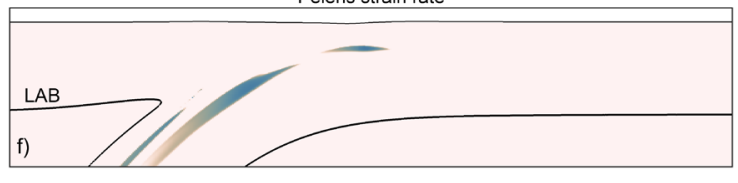

Viscosity

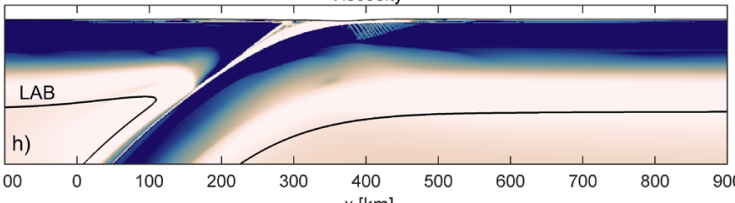

$\log _{10} \eta[\mathrm{Pa} \mathrm{s}]$

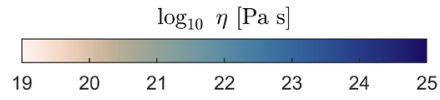

984 Figure 8. Zoom into the subduction zone of the forced subduction model for the time step corresponding to Fig. 7c. In panels

985 (a-f) the results of individual strain rates for the different deformation mechanisms are displayed. Panel (a) shows total strain

986 rate, (b) elastic strain rate, (c) plastic strain rate, (d) diffusion strain rate, (e) dislocation strain rate and (f) Peierls strain rate.

987 Panel (g) shows distribution of deformation mechanism (elastic domain in yellow, plastic domain in light blue, dislocation

988 creep in red, Peierls creep in dark blue and diffusion creep in orange) and panel (h) shows effective viscosity (Equation 15).

White or black lines correspond to the thermally controlled $L A B\left(1^{\prime} 440^{\circ} \mathrm{C}\right.$ isotherm). 


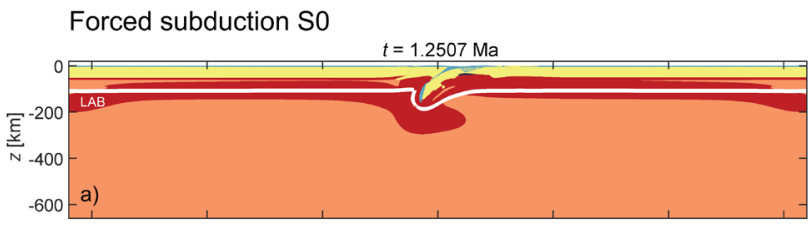

Free subduction $\mathrm{S} 1$
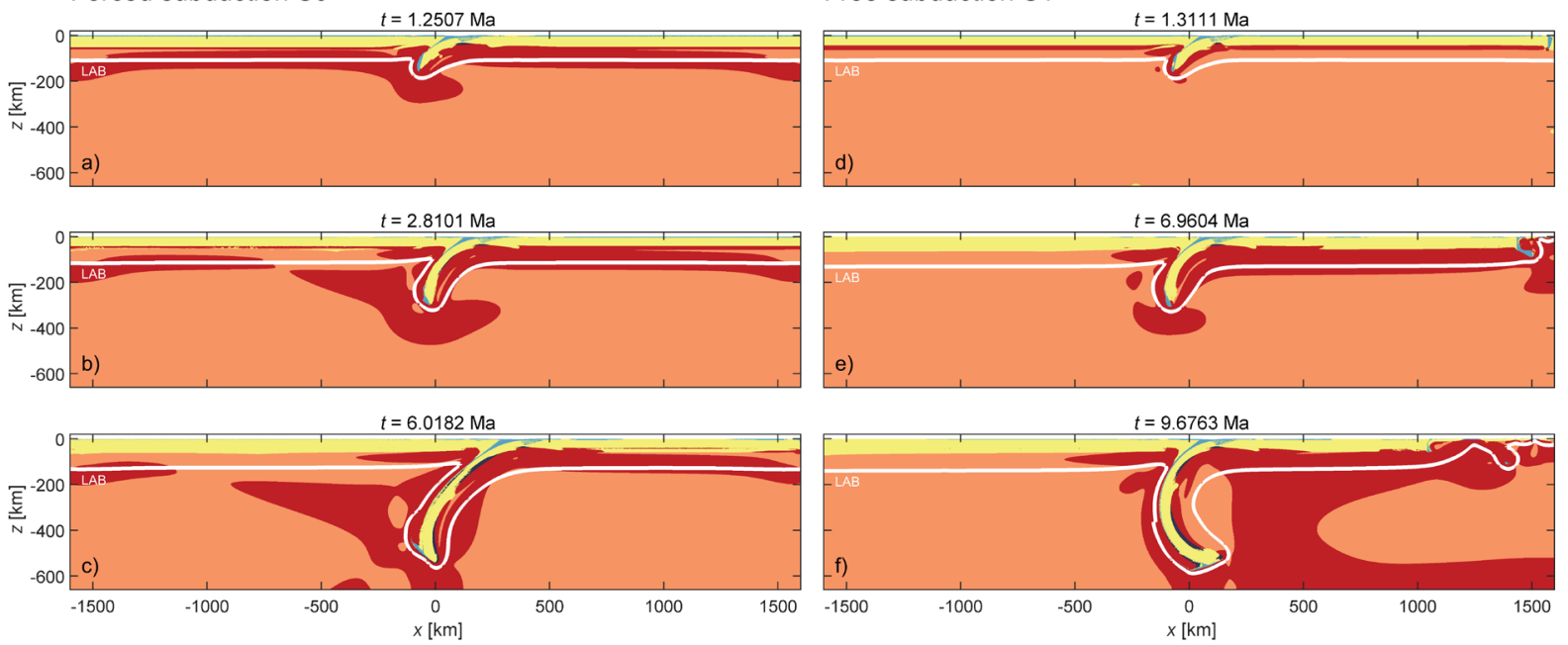

Distribution of deformation mechanisms

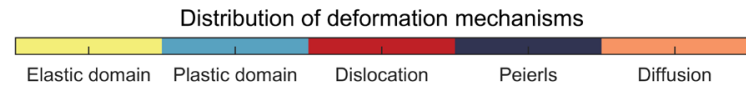

993 Figure 9. Distribution of deformation mechanism evolution for the forced subduction model, (a-c), and for the free

994 subduction model, (d-f), same time as Figs $3 a-f$. White lines correspond to the thermally controlled $L A B\left(1^{\prime} 440^{\circ} \mathrm{C}\right.$ isotherm). 


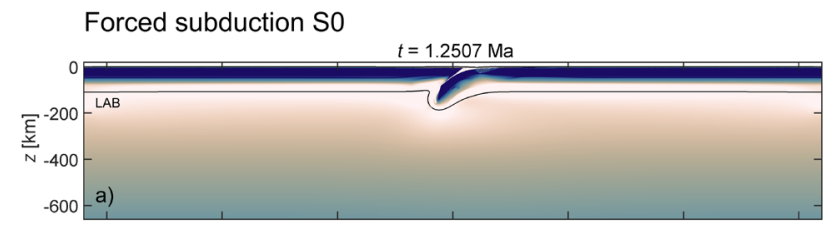

Free subduction S1
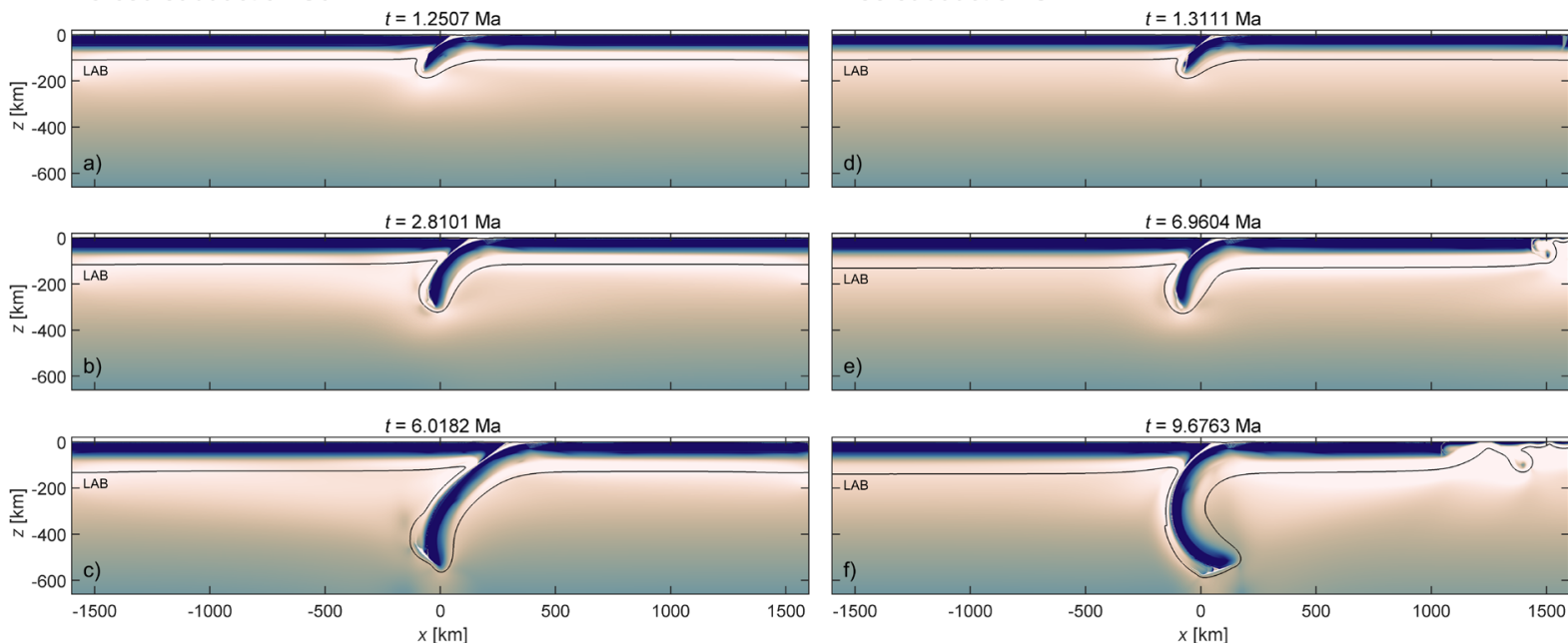

997

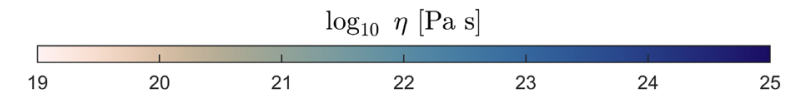

998 Figure 10. Effective viscosity evolution for the forced subduction model, (a-c), and for the free subduction model, (d-f), same

999 time as Figs 3a-f. Black lines correspond to the thermally controlled LAB $\left(1^{\prime} 440^{\circ} \mathrm{C}\right.$ isotherm). 


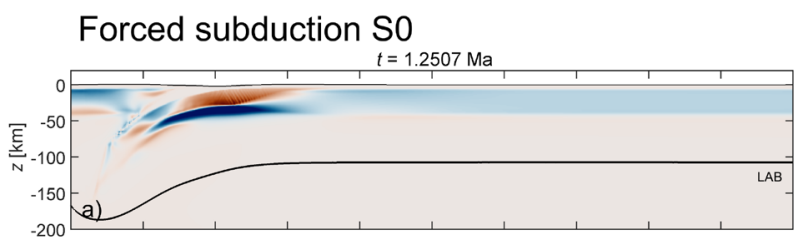

Free subduction $\mathrm{S} 1$
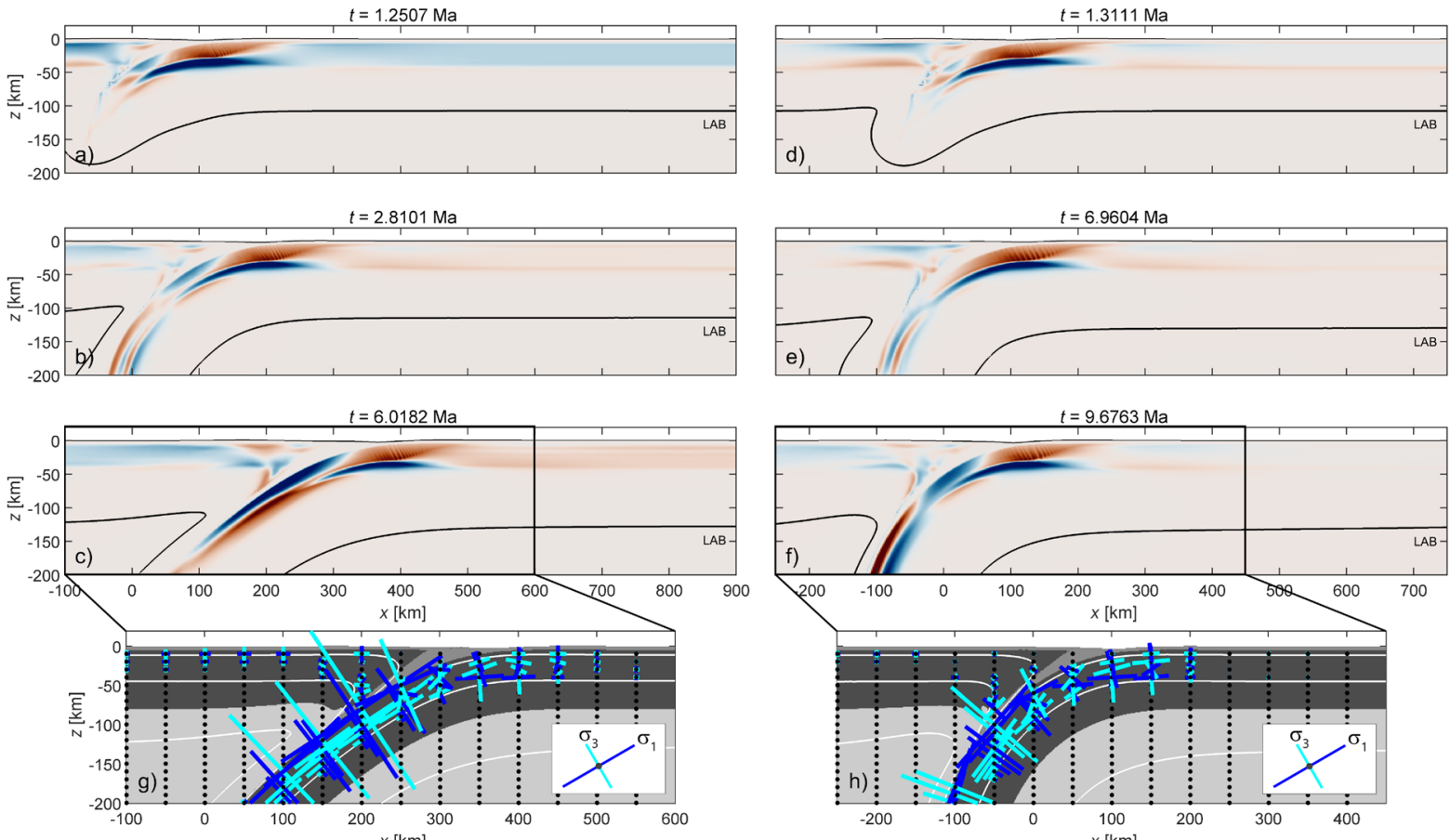

$\tau_{x x}[\mathrm{MPa}]$
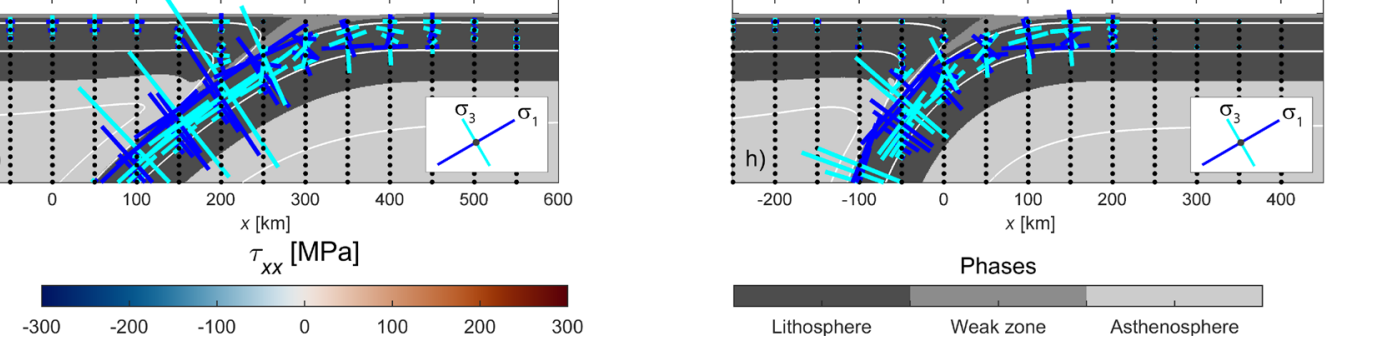

1003 Figure 11. Comparison of horizontal deviatoric stress between the forced subduction model (panels a-c) and the free

1004 subduction model (panels $d-f$ ) depicted at similar time as Figs 3a-f. Black lines correspond to the thermally controlled LAB

$\left(1^{\prime} 440^{\circ} \mathrm{C}\right.$ isotherm). Areas in red, positive values, show regions associated with extension while areas in blue, negative values, 

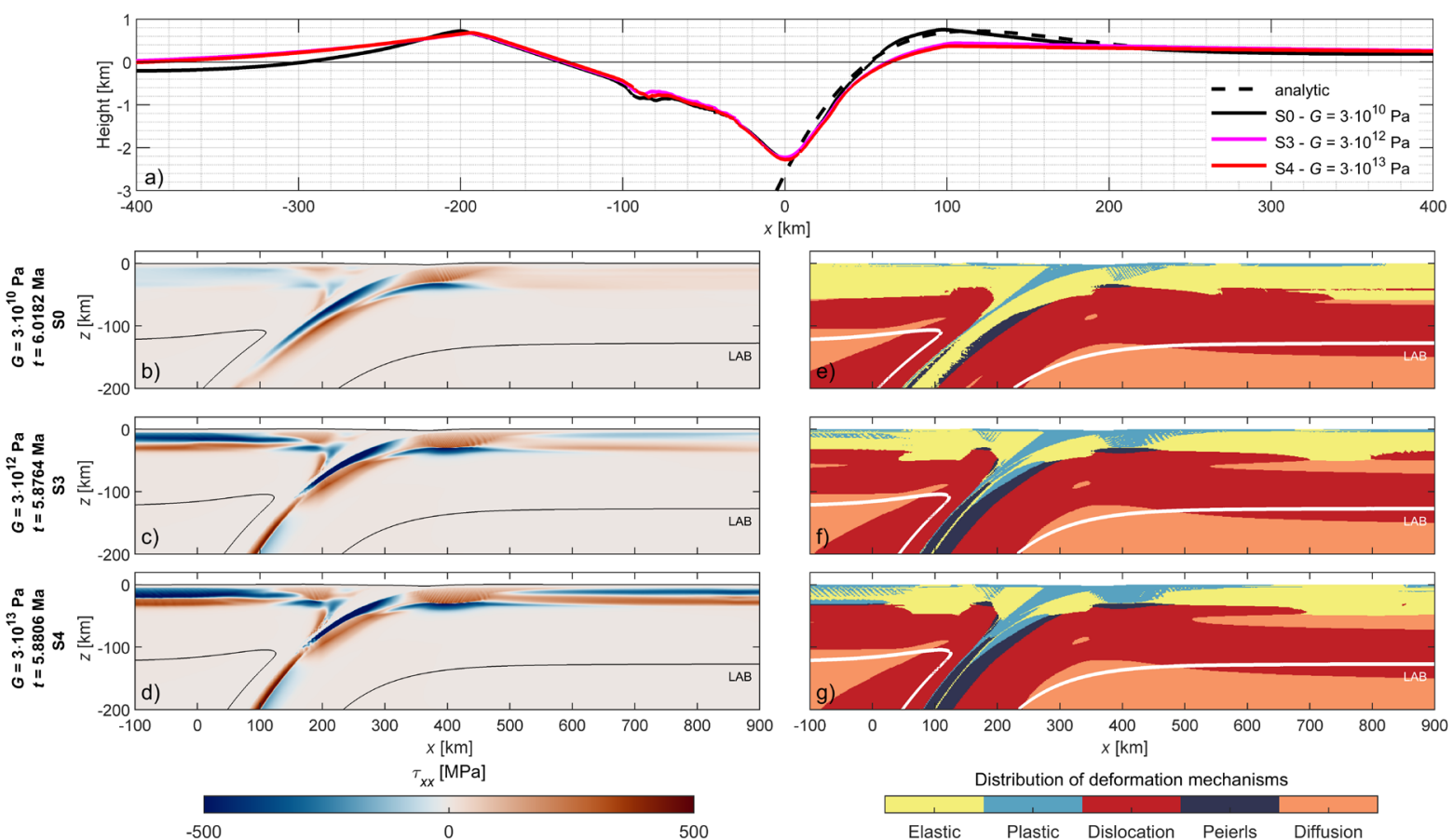

Figure 12. Comparison between three forced subduction models with different elasticity parameters. Results of simulation SO correspond to the black topography profile in panel (a), the horizontal deviatoric stress in panel (b) and the distribution of deformation mechanisms in panel (e). Results of simulation S3, with an unrealistically high shear modulus of $G=3 \cdot 10^{12}$, correspond to the pink topography profile in panel (a), the horizontal deviatoric stress in panel (c) and the distribution of deformation mechanisms in panel (f). Results of simulation S4, with an unrealistically high shear modulus of $G=3 \cdot 10^{13}$, correspond to the red topography profile in panel (a), the horizontal deviatoric stress in panel (d) and the distribution of deformation mechanisms in panel (g). Time step for panels (b) and (e) are the same as in Fig. 3c. Time step for panels (c and $f)$ and ( $d$ and $g$ ) are chosen to have approximately the same depth of the slab as in panels ( $b$ and e) for reference. The dashed line in panel (a) shows the best fit of elastic flexure from the analytical formula from Turcotte \& Schubert (2014) (Fig. 3.35 and equation 3.159, $x_{b}=55 \mathrm{~km}$ and $w_{b}=0.5 \mathrm{~km}$ ). In panel (a) the horizontal position of the zero was displaced to match the position of the trench (but not for the other panels). In panels (b-d) areas in red, positive values, show regions associated with extension while areas in blue, negative values, show compression. In panels $(b-g)$ white or black lines correspond to the thermally controlled $L A B\left(1^{\prime} 440^{\circ} \mathrm{C}\right.$ isotherm). 

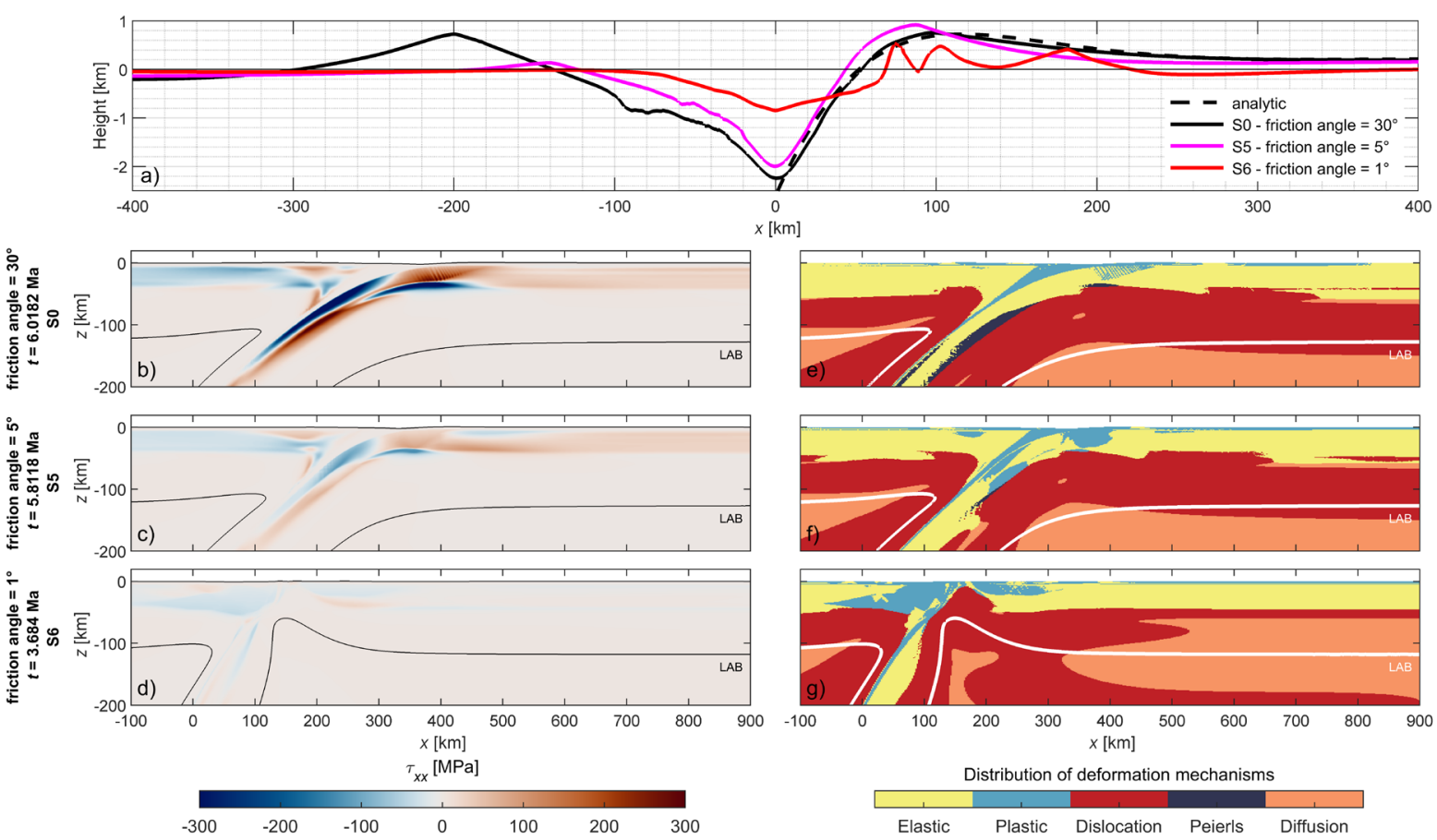

Figure 13. Comparison between three forced subduction models where we change the friction angle of the lithosphere. Results

of simulation SO correspond to the black topography profile in panel (a), the horizontal deviatoric stress in panel (b) and the distribution of deformation mechanisms in panel (e). Results of simulation 55 correspond to the pink topography profile in panel (a), the horizontal deviatoric stress in panel (c) and the distribution of deformation mechanisms in panel (f). Results of simulation S6 correspond to the red topography profile in panel (a), the horizontal deviatoric stress in panel (d) and the distribution of deformation mechanisms in panel (g). Time step for panels (b) and (e) are the same as in Fig. 3c. Time step for panels ( $c$ and $f$ ) and ( $d$ and $g$ ) are chosen to have the same depth of the slab than in panels ( $b$ and e) as reference. Same references as in Fig. 12 for the dashed line in panel (a). The horizontal position of the zero in panel (a) is displaced to correspond to the position of the trench (but not for the other panels). In panels (b-d) areas in red, positive values, show regions associated with extension while areas in blue, negative values, show compression. In panels (b-g) white or black lines correspond to the thermally controlled $L A B\left(1^{\prime} 440^{\circ} \mathrm{C}\right.$ isotherm). 


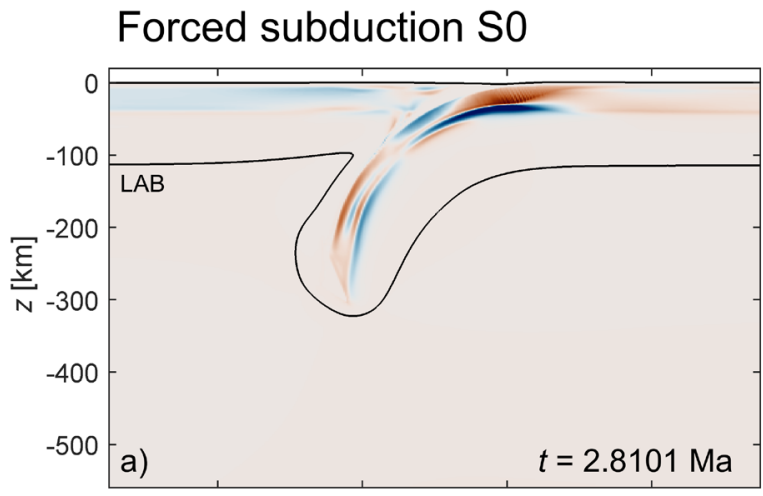

Free subduction S1
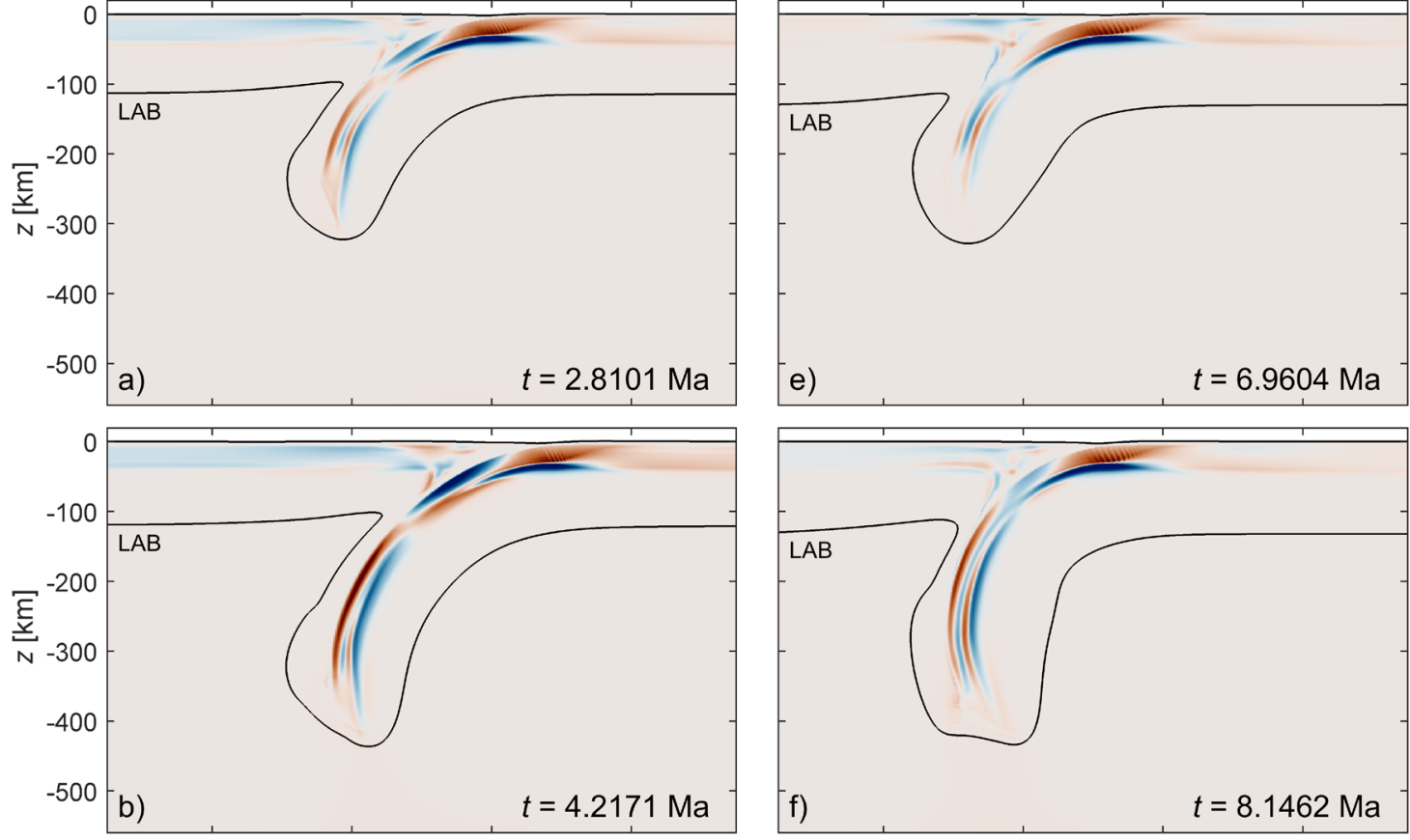

\section{Forced subduction S7}
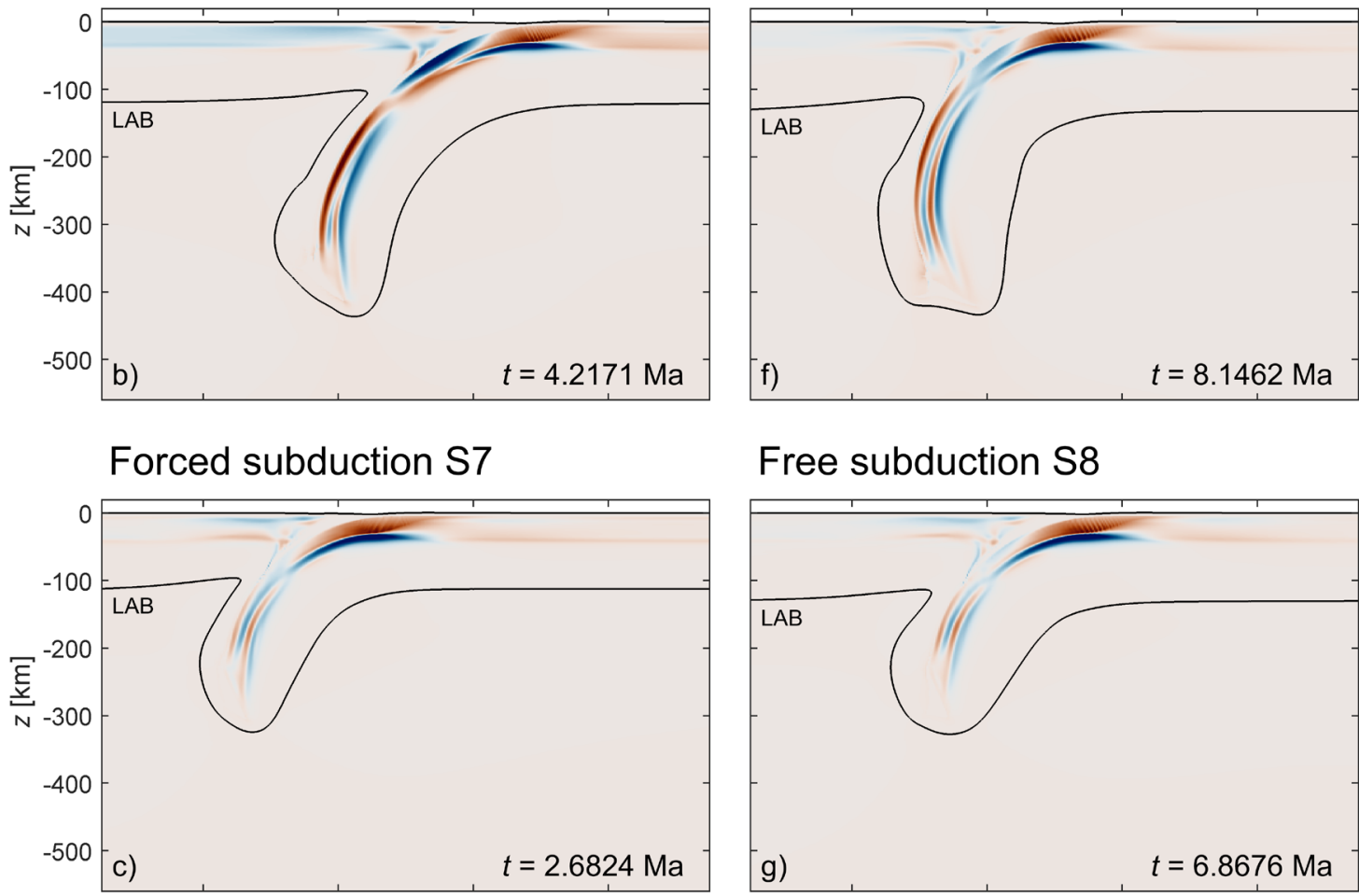

Free subduction S8
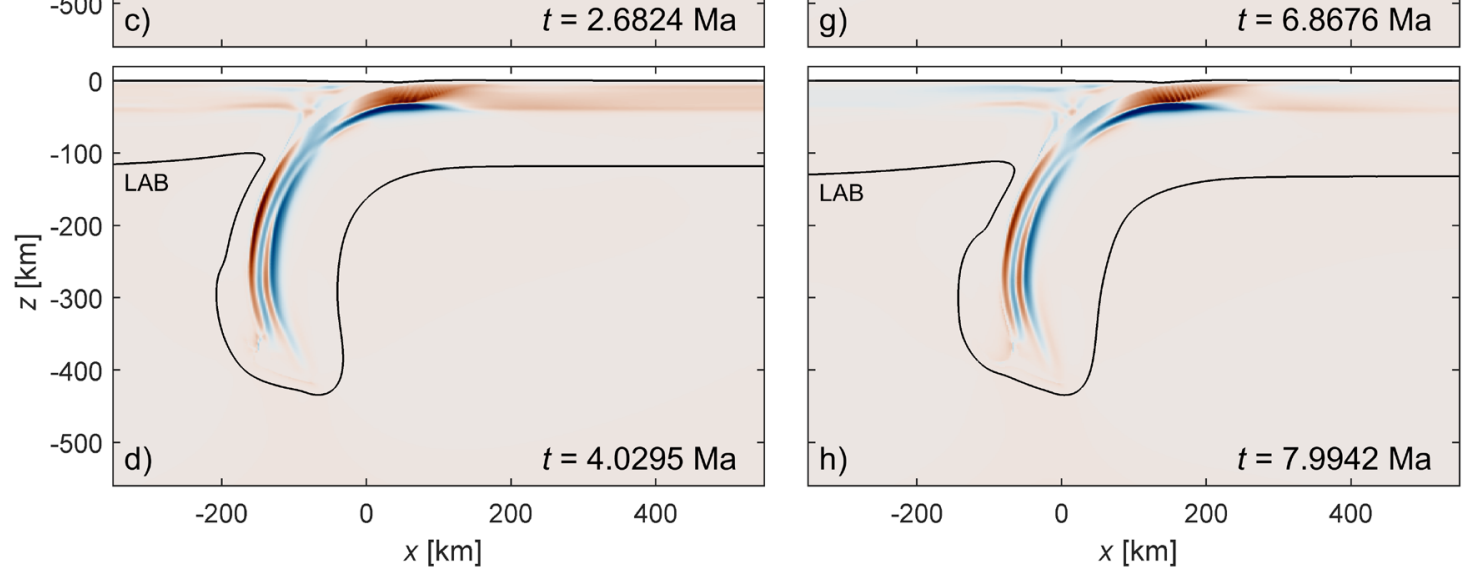

$\tau_{x x}[\mathrm{MPa}]$

Figure 14. Colour plot of horizontal deviatoric stress for forced and free subduction with different boundary conditions. 
1042 applied on both sides of the model. Panels (c) and (d) show results of the same forced simulation, except that a horizontal

1043 boundary velocity is only applied on the right side of the model (simulation S7, Table 2). This velocity is twice as large as the

1044 one of model SO to maintain the same absolute convergence velocity. Panels (e) and (f) show results of free simulation S1

1045 corresponding to the model where the lateral detachment of the slab by a weak zone is implemented at the right side of the

1046 model. Panels $(\mathrm{g})$ and $(\mathrm{h})$ show results of a free simulation where this detachment is applied at both sides of the model (S8).

1047 Time step for panels (a), (b), (e) and (f) same as Figs $3 b, c$, e and $f$. Time step for panels (c), (d), (g) and ( $h$ ) are chosen to

1048 have the same corresponding depth of the slab (310 km and $425 \mathrm{~km})$ for comparison. The areas in red, positive values, show

1049 regions associated with extension while areas in blue, negative values, show compression. Black lines correspond to the thermally controlled $L A B\left(1^{\prime} 440^{\circ} \mathrm{C}\right.$ isotherm).

1051 


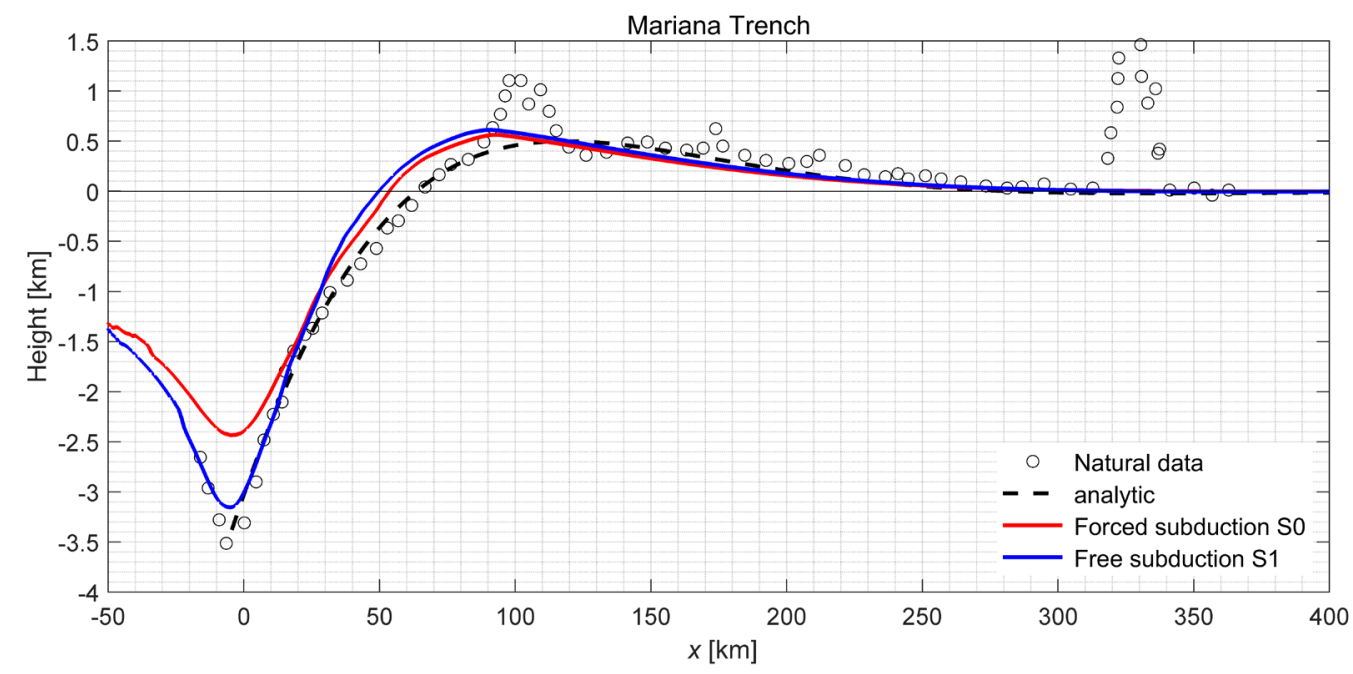

1053 Figure 15. Comparison of the topography of the Mariana trench with modelled topography for the forced (SO) and free (S1) 1054 subduction models. The dashed line shows the best fit of elastic flexure from Turcotte \& Schubert (2014) (Fig. 3.35 and equation 3.159, $x_{b}=55 \mathrm{~km}$ and $\left.w_{b}=0.5 \mathrm{~km}\right)$. For comparison all topography profiles are co-located at the trench.

1056 

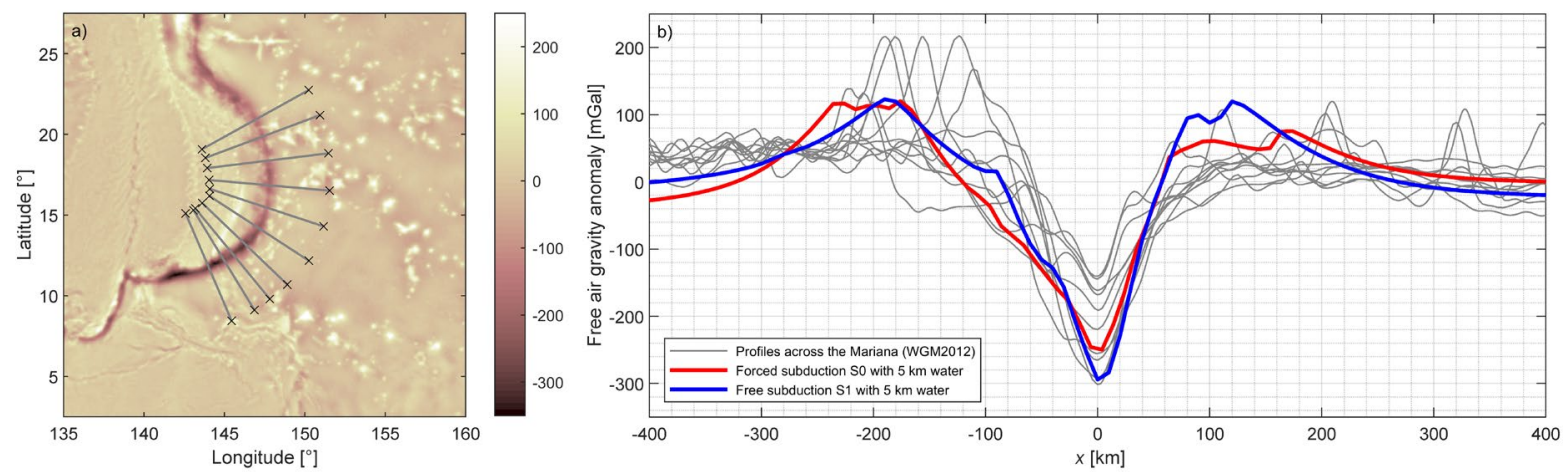

1058

1059 Figure 16. Free-air gravity anomaly comparison. Panel (a) shows the location of 10 different profiles across the Mariana

Trench, with the WGM2012 free-air anomaly map in the background. Panel (b) shows in grey the observed profiles across the

Mariana Trench, in red the synthetic profile from the forced subduction model for the time step corresponding to Fig. 3c, and

in blue the synthetic profile from the free subduction model for the time step corresponding to Fig. 3f. A zoom on the trench was chosen for the horizontal position and all profiles were centred on the trench. 
Adopted values of rheological and physical parameters

\begin{tabular}{|c|c|c|c|c|c|}
\hline \multicolumn{2}{|c|}{ Viscous rheology } & \multicolumn{4}{|c|}{ Lithosphere, Asthenosphere and Weak zone and weak hydrated crust } \\
\hline & & Dislocation & Diffusion & Peierls & Units \\
\hline$F$ & invariant formulation correction factor & $1 / 6 \cdot 2^{(1 / n) \cdot 3(n-1 / 2 n)}$ & $1 / 6 \cdot 2^{(1 / n) \cdot 3(n-1 / 2 n)}$ & $1 / 6 \cdot 2^{(1 / S) \cdot 3(S-1 / 2 S)}$ & - \\
\hline$A$ & pre-exponential constant & $1.1 \cdot 10^{-16}$ & $1.5 \cdot 10^{-15}$ & $5.7 \cdot 10^{11}$ & {$\left[\mathrm{~s}^{-1} \cdot \mathrm{Pa}^{-\mathrm{n}} \cdot \mathrm{m}^{\mathrm{m}}\right]$} \\
\hline$n$ & stress exponent & 3.5 & 1 & 2 & - \\
\hline$m$ & grain size exponent & 0 & 3 & - & - \\
\hline$E$ & activation energy & $530 \cdot 10^{3}$ & $375 \cdot 10^{3}$ & $5.4 \cdot 10^{5}$ & {$\left[\mathrm{~J} \cdot \mathrm{mol}^{-1}\right]$} \\
\hline$V$ & activation volume & $11 \cdot 10^{-6}$ & $4 \cdot 10^{-6}$ & 0 & {$\left[\mathrm{~m}^{3} \cdot \mathrm{mol}^{-1}\right]$} \\
\hline$\gamma$ & adjustable constant & - & - & 0.1 & - \\
\hline$\sigma_{\text {pei }}$ & the Peierls stress & - & - & $8.5 \times 10^{9}$ & {$[\mathrm{~Pa}]$} \\
\hline \multicolumn{2}{|c|}{ Plastic rheology } & Lithosphere & Asthenosphere & Weak zone / Sediments & \\
\hline C & cohesion & $1 \cdot 10^{7}$ & $1 \cdot 10^{6}$ & $1 \cdot 10^{6}$ & {$[\mathrm{~Pa}]$} \\
\hline$\theta$ & Angle of internal friction & 30 & 5 & 0 & {$\left[{ }^{\circ}\right]$} \\
\hline \multicolumn{6}{|c|}{ Constants } \\
\hline$R$ & universal gas constant & 8.31 & & & {$\left[\mathrm{~J} \cdot \mathrm{mol}^{-1} \cdot \mathrm{K}^{-1}\right]$} \\
\hline$\alpha$ & thermal expansion & $8 \cdot 10^{-6}$ & & & {$\left[K^{-1}\right]$} \\
\hline$\beta$ & compressibility & $1 \cdot 10^{-11}$ & & & {$\left[\mathrm{~Pa}^{-1}\right]$} \\
\hline$d$ & grain size & $5 \cdot 10^{-3}$ & & & [m] \\
\hline$H_{R}$ & radiogenic heat production & $1 \cdot 10^{-10}$ & & & {$\left[\mathrm{~W} \cdot \mathrm{m}^{-3}\right]$} \\
\hline G & shear modulus & $3 \cdot 10^{10}$ & & & {$[\mathrm{~Pa}]$} \\
\hline$g$ & gravity & 9.81 & & & {$\left[\mathrm{~m} \cdot \mathrm{s}^{-2}\right]$} \\
\hline
\end{tabular}




\begin{tabular}{|l|l|l|l|l|l|l|}
\hline & \multicolumn{6}{|c|}{ Parameters } \\
\hline Simulations & type & $t_{\text {free }}$ & elasticity & $\begin{array}{l}\text { friction angle } \\
\text { lithosphere }\end{array}$ & $\begin{array}{l}\text { Boundary } \\
\text { velocity }\end{array}$ & $\begin{array}{l}\text { Boundary } \\
\text { zone }\end{array}$ \\
\hline S0 (Ref) & forced & - & yes, $G=3 \cdot 10^{10} \mathrm{~Pa}$ & $30^{\circ}$ & both sides & none \\
\hline S1 & free & $1.25 \mathrm{Ma}$ & yes, $G=3 \cdot 10^{10} \mathrm{~Pa}$ & $30^{\circ}$ & none & right side \\
\hline S2 & free & $1.17 \mathrm{Ma}$ & yes, $G=3 \cdot 10^{10} \mathrm{~Pa}$ & $30^{\circ}$ & none & right side \\
\hline S3 & forced & - & yes, $G=3 \cdot 10^{12} \mathrm{~Pa}$ & $30^{\circ}$ & both sides & none \\
\hline S4 & forced & - & yes, $G=3 \cdot 10^{13} \mathrm{~Pa}$ & $30^{\circ}$ & both sides & none \\
\hline S5 & forced & - & yes, $G=3 \cdot 10^{10} \mathrm{~Pa}$ & $5^{\circ}$ & both sides & none \\
\hline S6 & forced & - & yes, $G=3 \cdot 10^{10} \mathrm{~Pa}$ & $1^{\circ}$ & both sides & none \\
\hline S7 & forced & - & yes, $G=3 \cdot 10^{10} \mathrm{~Pa}$ & $30^{\circ}$ & right side & none \\
\hline S8 & free & $1.25 \mathrm{Ma}$ & yes, $G=3 \cdot 10^{10} \mathrm{~Pa}$ & $30^{\circ}$ & none & left and right side \\
\hline
\end{tabular}

